Brazilian Journal

of Chemical

Engineering

\title{
INTEGRATING REAL TIME OPTIMIZATION AND MODEL PREDICTIVE CONTROL OF A CRUDE DISTILLATION UNIT
}

\author{
Paulo A. Martin ${ }^{1}$, Antonio C. Zanin ${ }^{2}$ and Darci Odloak ${ }^{3 *}$ \\ ${ }^{1}$ Instituto Mauá de Tecnologia, Engenharia Elétrica, São Caetano do Sul, SP, Brasil. E-mail: pauloalexandre@maua.br - \\ ORCID: 0000-0002-6604-2276 \\ ${ }^{2}$ Petrobras S.A., Centro de Excelência para Aplicação de Tecnologia em Automação Industrial, São Paulo, SP, Brasil. \\ E-mail: zanin@petrobras.com.br - ORCID: 0000-0002-9067-8442 \\ ${ }^{3}$ Universidade de São Paulo, Departamento de Engenharia Química, São Paulo, SP, Brasil. E-mail: odloak@usp.br - \\ ORCID: 0000-0001-7184-353X
}

(Submitted: November 17, 2017 ; Revised: June 29, 2018 ; Accepted: October 9, 2018)

\begin{abstract}
This work reports the integration of Real Time Optimization and Model Predictive Control in the multi-layer control structure of an existing Crude Distillation Unit (CDU) of an oil refinery. The MPC considers output control zones and targets for the inputs or outputs. Both the infinite horizon and the finite output horizon controllers were tested. The plant results show that the infinite horizon controller tends to perform similarly or better then the finite horizon MPC when the CDU system needs to operate at quite different conditions. Although the dynamic layer based on the infinite horizon controller is nominally stable for any set of tuning parameters, in practice, it is observed that the interaction between the layers of the control structure associated to model uncertainty may result in oscillations in some variables that fail to converge to the optimum operation point. This problem can be solved with the retuning of the intermediary layer (target calculation layer), which indicates that the frequent tuning of the MPC is recommended and should be performed in conjunction with tuning of the intermediary layer.

Keywords: Crude distillation unit; Infinite horizon MPC; Integration of RTO and MPC.
\end{abstract}

\section{INTRODUCTION}

The crude oil distillation unit (CDU) is one of the key process systems of the oil industry. The main functionality of the CDU is to separate the crude oil fractions according to their boiling point ranges. The operation of the crude distillation equipment demands large amounts of energy while producing a multitude of products. The optimization of the operation of the CDU becomes more complicated by the fact that the feedstock (crude oil) has a complex composition, consisting of a large number of hydrocarbons ranging from components with simple structures and low molecular weights, such as liquefied petroleum gas, to components with complex structures and large molecular weights such as diesel oil.

The need of energy conservation and the different market values of the CDU products result in a challenge to perform the optimization of the operating conditions. Besides, in the operation of the CDU, the quality specifications of the products has to be maintained, and several process variables are to be kept inside well defined ranges despite the disturbances that affect the process. This results in the consideration of complex control structures that aim at the reduction of the variability of the intermediary products in order to reach an operation point, which is close to equipment constraints to maximize their utilization and the economic benefit. The number of

\footnotetext{
* Corresponding author: Darci Odloak - E-mail: odloak@usp.br
} 
applications of complex control structures based on MPC (Model Predictive Control) in oil refineries, which includes the CDU process, amounts to thousands (Qin and Badgwell, 2003). Also, several studies can be found in the process control literature about the design and application of MPC in the crude distillation unit (Pannocchia et al., 2006; Kemalöglu et al., 2009; Mingjian, et al., 2007; Sun and Sun, 2006; Nogueira and Trivella, 2002). Some studies focus on the integration of real time optimization and MPC (Jones, et al., 1999; Hou et al., 2001).

The control structure of the CDU considered here is represented in Fig. 1 and follows the multilayer approach, where $\left(u_{R T O}, y_{R T O}\right)$ are the values of the input and output variables that define the optimum point. The RTO layer that computes the optimum operating point is not part of this study, which deals only with the two lower layers. The objective function of the RTO problem corresponds to the economic profit of the crude distillation system at steady-state. The optimum values computed by the RTO are passed to the intermediary layer that recomputes these targets based on a linear steady-state model, the input and output constraints and the latest information about the plant input and output. The main role of the target calculation layer is to compute feasible targets for the control layer, because the RTO runs at a low frequency and the RTO targets may become infeasible because of disturbances. These updated targets $\left(u_{d e s}, y_{d e s}\right)$ are then passed to the MPC layer that calculates the control actions $(u(k))$ to be implemented in the real process. The industrial CDU system studied here has hosted several experiments concerning the development and implementation of advanced control strategies. For instance, a method for the tuning of a conventional MPC that was previously implemented in the CDU was reported in Yamashita et al. (2016).

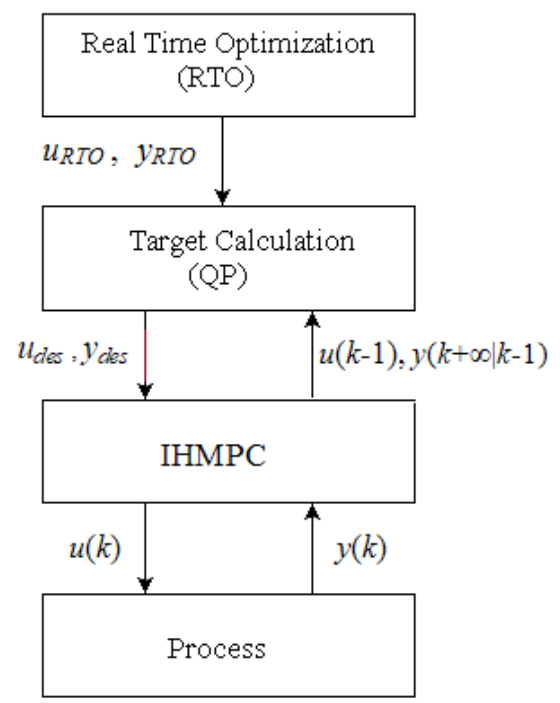

Figure 1. Integration of RTO and MPC (Alvarez and Odloak, 2010).
In the structure represented in Fig. $1, u(k-1)$ is the last control action that was implemented in the real plant and $y(k+\infty \mid k-1)$ is the steady-state output prediction calculated at the previous time step.

The structure represented in Fig. 1 can be considered conventional and is usually adopted in oil refineries. In this structure, a finite horizon MPC is usually considered. The main novelty of this work is the consideration of an Infinite Horizon Model Predictive Control (IHMPC). Although the IHMPC has been extensively studied in the literature (Rawlings and Muske, 1993; Santoro and Odloak, 2012; González and Odloak, 2009) there is a lack of reported industrial applications of this sort of control algorithm (Forbes et al., 2015; Lee, 2011). So, it seems interesting to test if an IHMPC that was developed in the academia can have a satisfactory performance in a real application. The potential advantage of the IHMPC over the conventional MPC is the nominal stability of the closed-loop system, which means that, if the process being controlled is perfectly represented by the linear model considered in the controller, then the closed-loop will be stable no matter the adopted tuning parameters of the controller. This does not mean that IHMPC will not require an adequate tuning, but the tuning procedure may be easier than with the finite horizon controller, or the controller may tolerate a more aggressive tuning. Although the perfect model is rarely found in practice, nominal stability is a desirable property of any controller to be implemented in industry (Qin and Badgwell, 2003). Besides, another possible advantage of the infinite horizon controller is the existing theoretical framework that concerns the robust MPC to model uncertainty (Mayne et al., 2011; Ferramosca et al., 2012; Martins and Odloak, 2016). So, this work can also be considered as an intermediary step towards the practical application of a robust MPC.

This paper is presented as follows: in section 2, the CDU process and the operating objectives of the system considered here are described. In section 3 the control structure is described in more details. Particularly, the optimization problems that are solved in the target calculation layer and in the IHMPC layer are presented and discussed. The main differences between the conventional and the infinite horizon MPC are also discussed. In section 4, additional details about the CDU considered in this study are presented, as well as some practical results obtained in the real system, mainly the comparison of the structures with the two controllers are presented and discussed. Finally, in section 5, the paper is concluded.

\section{THE CRUDE DISTILLATION UNIT OF THE CAPUAVA REFINERY}

The industrial CDU considered in this work is schematically represented in Fig. 2. This system 


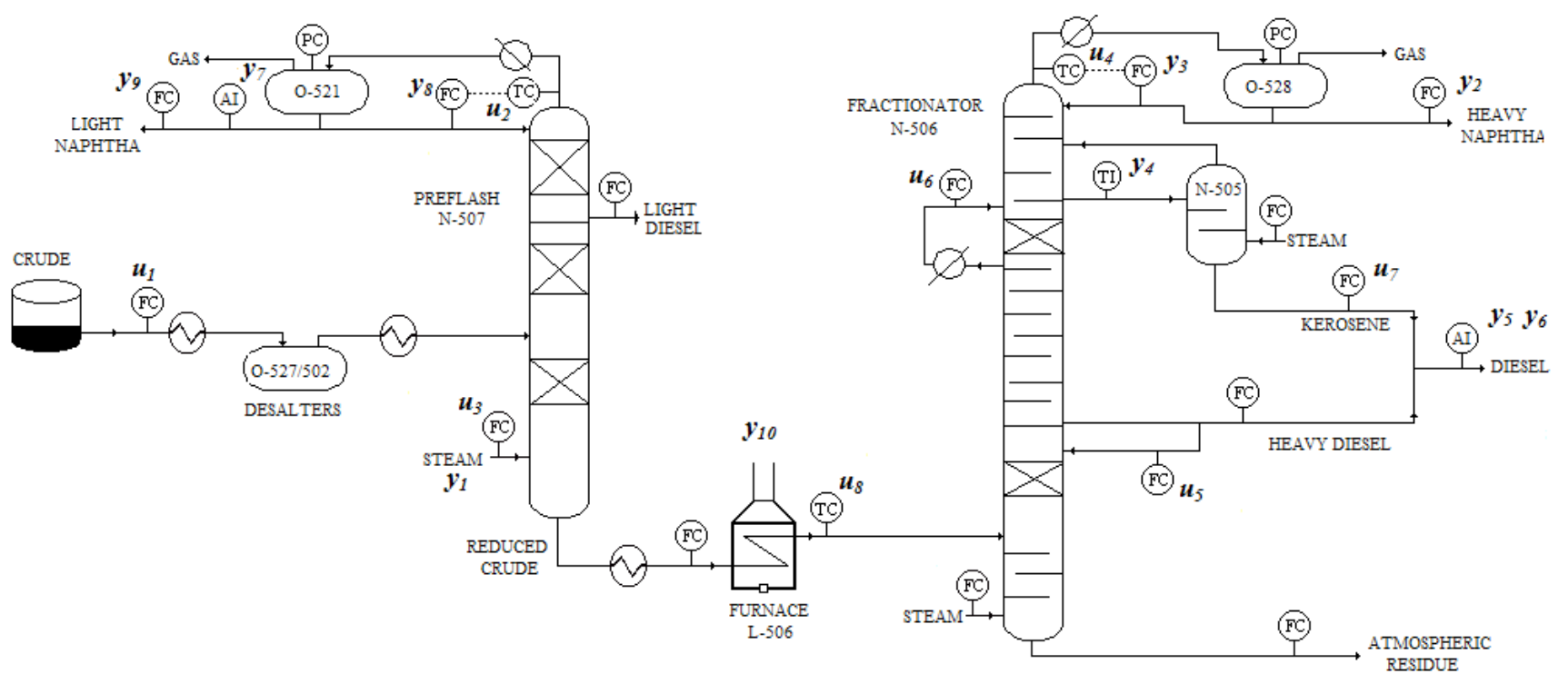

Figure 2. Schematic Representation of the Crude Distillation Unit of the Capuava Refinery.

was also considered in the development of a tuning method for the finite horizon MPC (Yamashita et al., 2016). Typically, a crude distillation unit involves the crude preheating train, a pre-flash column, oil furnaces and the atmospheric distillation column. In the crude preheating trains, the crude is heated by hot product streams such as the diesel oil product and the pumparound reflux. The crude coming from the crude tanks is desalted, preheated and partially vaporized before being introduced in the preflash column. At the top of this column, two light hydrocarbon streams are produced, the refinery gas that mainly consists of methane and ethane and the light naphtha stream. The naphtha is sent to the Solvent Unit where liquefied petroleum gas (LPG) is produced to be utilized mainly for cooking and several types of solvents such as rubber solvent are also produced. To comply with the specification of the solvent to be produced, the distillation ASTM D86 endpoint of the naphtha must be kept below a maximum value. The flow rate of the light naphtha stream has to be kept above a minimum constraint to guarantee that the required amount of solvent will be produced. Also, to allow a suitable fractionation at the top of the column, the reflux flow rate should be controlled inside a pre-defined range and this can be done through the manipulation of the temperature at the top of the column.

The preflash column has a side draw where an intermediary naphtha stream (light diesel) can be produced when the refinery operation objective is to maximize the production of diesel. The naphtha stream is incorporated into the diesel pool. The role of this side draw is to alleviate the heat load of the oil furnace and to allow the increase of the amount of crude that can be processed.

To prevent the light components to be carried by the reduced crude, live superheated steam is introduced in the bottom section of the preflash column. This steam leaves the preflash column as liquid water in the liquid-liquid separation system in the overhead drum. The ratio between the flow rates of steam and reduced crude must be kept inside a suitable range to guarantee the efficiency of the stripping of the light components. Also, to produce a control strategy where energy is minimized, the flow rate of the stripping steam must be manipulated.

The reduced crude that leaves the bottom of the preflash column is directed to the furnace where it is partly vaporized and injected into the atmospheric column. To protect the furnace integrity, the heat load must be controlled in a suitable range and this is basically done through the manipulation of the temperature of the oil outlet stream.

At the top of the atmospheric distillation column, there is the production of heavy naphtha that becomes part of the gasoline pool. To guarantee the fractionation at the top of the atmospheric column, the top reflux flow is kept inside suitable bounds through the manipulation of the set point to the temperature controller at the top of the column. The diesel fraction that is produced in the atmospheric column is a blend of the two side streams of the column: the kerosene stream and the heavy diesel stream. The amount of diesel that is produced is defined through the manipulation of the fractionator top temperature, furnace outlet temperature and flow rate of the heavy diesel reflux. The flash point of the diesel product is controlled through the manipulation of the set point of the PID controller of the temperature at the top of the atmospheric column. The ASTM D-86 95\% is another important specification of the diesel product and is mainly controlled through the manipulation of the heavy diesel reflux and the furnace outlet temperature. There is a pumparound reflux at the diesel zone of the 
atmospheric column. This reflux is manipulated to keep the fractionation along the column and to improve the recovery of heat at the crude preheating section.

The liquid hydrocarbon stream that leaves the bottom of the atmospheric column is the atmospheric residue that is the main component of feed to the RFCC unit.

In the standard operation of the CDU plant considered here, the Real Time Optimization (RTO) layer is based on a rigorous steady-state model of the crude distillation process and maximizes the economic benefit by setting target values for:

- the ratio between the flow rate of the stripping steam to the bottom of the preflash column and the flow rate of reduced crude

- the crude feed flow rate

- the temperature at the top of the preflash column

- the temperature at the top of the atmospheric column

- the flow rate of the heavy diesel reflux

- the flow rate of the heavy diesel pumparound

- the flow rate of the kerosene withdraw

- the crude furnace outlet temperature

The main disturbance to the control structure of the CDU is the composition of the crude oil. Once a change in the crude composition is detected by the crude analyzer and the system reaches the steady-state, the RTO layer computes a new optimum operating point for the target calculation layer, which at each sampling period computes new targets for the IHMPC.

The implementation details of the commercial RTO package that performs the optimization of the crude distillation unit is not included in this study. The scope here is to study how the infinite or finite horizon MPC will cope with the economic targets provided by the RTO for some of the inputs, while considering control zones for most of the outputs.

\section{THE CONTROL STRUCTURE OF THE CDU}

In the control structure represented in Fig. 1, the RTO layer solves an optimization problem based on a rigorous nonlinear model of the CDU. In the industrial unit considered here, the RTO package aspenONE with the Aspen Plus Optimizer was implemented to produce the optimum operating point of the CDU. We concentrate on the target calculation layer and on the MPC layer assuming that the optimum values of $u_{R T O}$ and $y_{R T O}$ are known to the target calculation layer as represented in Fig. 1.

The target calculation layer and the MPC layer were implemented in the Petrobras control package SICON, which is the standard control package of Petrobras for MPC applications in oil refineries. At each time step $k$, the target calculation layer solves the following optimization problem:

$$
\begin{aligned}
\min _{\mathrm{u}_{\text {des },}, \mathrm{ydes}_{\text {des }}, \mathrm{T}_{\mathrm{y}}} \mathrm{V}_{\mathrm{TCL}, \mathrm{k}} & =\left\|\mathrm{y}_{\mathrm{RTO}}-\mathrm{y}_{\mathrm{des}}\right\|_{\mathrm{W}_{\mathrm{y}}}^{2}+\left\|\mathrm{u}_{\mathrm{RTO}}-\mathrm{u}_{\text {des }}\right\|_{\mathrm{W}_{\mathrm{u}}}^{2}+ \\
& +\|\Delta \mathrm{u}\|_{\mathrm{W}_{2}}^{2}+\left\|\delta_{\mathrm{y}}^{\mathrm{TCL}}\right\|_{\mathrm{W}_{3}}^{2}
\end{aligned}
$$

subject to

$$
\begin{aligned}
& \mathrm{y}_{\text {des }}=\mathrm{y}(\mathrm{k}+\infty \mid \mathrm{k}-1)+\mathrm{K} \Delta \mathrm{u} \\
& \mathrm{u}_{\text {des }}=\mathrm{u}(\mathrm{k}-1)+\Delta \mathrm{u} \\
& \mathrm{u}_{\text {min }} \leq \mathrm{u}_{\text {des }} \leq \mathrm{u}_{\max } \\
& -\mathrm{m} \Delta \mathrm{u}_{\max } \leq \Delta \mathrm{u} \leq \mathrm{m} \Delta \mathrm{u}_{\text {max }} \\
& \mathrm{y}_{\min } \leq \mathrm{y}_{\text {des }}+\delta_{\mathrm{y}}^{\mathrm{TCL}} \leq \mathrm{y}_{\max }
\end{aligned}
$$

where $y_{d e s}$ and $u_{\text {des }}$ are the desired output and input that are compatible with the linear static model of the process and the operating constraints, $\Delta u$ is the input target increment that is penalized in the objective function to force a smooth operation, $\delta_{y}{ }^{T C L}$ is the output slack variable, $u(k-1)$ is the last implemented input and $y(k+\infty \mid k-1)$ is the predicted output steady-state at the previous time instant $k-1, K$ is the open-loop static gain matrix of the system. Although $K$ could be updated with the gain resulting from the linearization of the nonlinear model considered in the RTO layer, the adaptive gain is not considered here because the existing RTO package does not provide such information. Weight matrices $W_{y}$ and $W_{u}$ penalize the deviations of the output and input targets from their optimum resting values defined by the RTO layer. Weight matrix $W_{2}$ penalizes large changes of the input target from the present value of the input. The slack variable $\delta_{y}{ }^{T C L}$ that is penalized with weight $W_{3}$ is included in the optimization problem defined in (1)-(5) to guarantee that it will be always feasible. If this slack variable was not included in constraint (5), there could be a conflict between the input constraints defined in (4a) and (4b) and the output constraint defined in (5). This conflict could turn the target calculation problem unfeasible. Constraint (4b) concerns the input move limitation imposed by the MPC layer, where $m$ is the input horizon and $\Delta u_{\max }$ is the maximum input move. Observe that the problem solved in the target calculation layer is a $\mathrm{QP}$ and, if $W_{2}=0$ and no constraints become active, it has a trivial solution $\left(\mathrm{y}_{\text {des }}=\mathrm{y}_{\mathrm{RTO}}, \mathrm{u}_{\mathrm{des}}=\mathrm{u}_{\mathrm{RTO}}\right)$. However, because of the penalization of large moves of the input targets, and the presence of the constraint related to $\Delta u_{\max }$, the response of the target calculation layer may converge to the RTO targets $\left(\mathrm{y}_{\mathrm{RTO}}, \mathrm{u}_{\mathrm{RTO}}\right)$ more slowly, inducing a sort of dynamics to this layer that deals with the predicted steady-state only. 
When the infinite horizon controller is implemented with input targets and output control zones in an openloop stable system such as the CDU, the optimization problem that is solved by the IHMPC can be written as follows:

$$
\begin{aligned}
\min _{\Delta u_{k}, y_{s p, k}, \delta_{y, k}, \delta_{u, k}} V_{k} & =\sum_{j=0}^{\infty}\left\|y(k+j \mid k)-y_{s p, k}-\delta_{y, k}\right\|_{Q_{y}}^{2}+ \\
& +\sum_{j=0}^{\infty}\left\|u(k+j \mid k)-u_{\text {des }}-\delta_{u, k}\right\|_{Q_{u}}^{2}+ \\
& +\sum_{j=0}^{m-1}\|\Delta u(k+j \mid k)\|_{R}^{2}+\left\|\delta_{y, k}\right\|_{S_{y}}^{2}+\left\|\delta_{u, k}\right\|_{S_{u}}^{2}
\end{aligned}
$$

subject to

$$
\begin{aligned}
& -\Delta \mathrm{u}_{\max } \leq \Delta \mathrm{u}(\mathrm{k}+\mathrm{j} \mid \mathrm{k}) \leq \Delta \mathrm{u}_{\max }, \mathrm{j}=0,1, \ldots, \mathrm{m}-1 \\
& \mathrm{u}_{\min } \leq \mathrm{u}(\mathrm{k}+\mathrm{j} \mid \mathrm{k}) \leq \mathrm{u}_{\max }, \mathrm{j}=0,1, \ldots, \mathrm{m}-1 \\
& \mathrm{y}_{\min } \leq \mathrm{y}_{\mathrm{sp}, \mathrm{k}} \leq \mathrm{y}_{\max }
\end{aligned}
$$

$\mathrm{y}(\mathrm{k}+\infty \mid \mathrm{k})-\mathrm{y}_{\mathrm{sp}, \mathrm{k}}-\delta_{\mathrm{y}, \mathrm{k}}=0$ for the outputs without targets

$\left.\begin{array}{l}\mathrm{y}_{\mathrm{sp}, \mathrm{k}}=\mathrm{y}_{\mathrm{des}} \\ \delta_{\mathrm{y}, \mathrm{k}}=\delta_{\mathrm{y}}^{\mathrm{TCL}}\end{array}\right\}$ for the outputs with optimizing targets

$\mathrm{u}(\mathrm{k}+\mathrm{m}-1 \mid \mathrm{k})-\mathrm{u}_{\mathrm{des}}-\delta_{\mathrm{u}, \mathrm{k}}=0$ for the inputs with targets

where $\mathrm{Q}_{\mathrm{y}}>0, \mathrm{Q}_{\mathrm{u}} \geq 0, \mathrm{R} \geq 0, \mathrm{~S}_{\mathrm{y}}>0$ and $\mathrm{S}_{\mathrm{u}} \geq 0$ are diagonal weighting matrices that should be properly selected; $y(k+j \mid k)$ is the prediction of the output at time step $k+j$ performed at time $k$, the adopted dynamic model that relates the output predictions with the input will be presented at the end of this section; $y_{s p, k}$ is the computed output set-point that should lie inside the control zone defined through constraint (9); $\Delta u_{k}=\left[\Delta u(k \mid k)^{T} \ldots \Delta u(k+m-1 \mid k)^{T}\right]^{T}$ is the control sequence that is computed at each time step where only the first control action is implemented in the real system and $m$ is the control horizon. Constraints (7) and (8) correspond to bounds on the manipulated input moves and input bounds. Also, it can be shown that, with constraints (10) and (12), the infinite summation terms of the objective function defined in Equation (6) can be transformed into finite summation terms that go up to the end of the control horizon. Equations (10) and (11) mean that the predicted output at steady-state should be equal to the set-point, while Eq. (12) means that the input at the end of the control horizon should be equal to the input target.

Slacks $\delta_{y, k}$ and $\delta_{u, k}$ are included to guarantee that these constraints will remain feasible. Observe that if one needs to force a target for an output, then constraint (9) has to be replaced with constraint (11) for this particular output. It should be observed that the number of inputs plus outputs that have optimum targets should not be larger than the degrees of freedom of the process system being controlled, which is equal to the number of manipulated inputs. Observe that $\delta_{v}^{T C L}$ is the slack that characterizes the offset of the output in the static problem solved in the target calculation layer. Also, $\delta_{y, k}$ is the slack that characterizes the offset of the predicted output at steady-state in the dynamic problem solved in the infinite horizon controller. Then, both slacks refer to the output offset at steady-state and the second equation of constraint (11) forces them to be the same for those outputs that have optimum targets. One should also note that, for those inputs that do not have targets, the corresponding entries in weight matrix $Q_{u}$ should be made equal to zero.

It can be shown (Alvarez \& Odloak, 2010) that, in the case where there is no model uncertainty, the sequential solution of problems (1-5) and (6-12) leads to the convergence of the inputs and outputs to their targets and the whole control structure is stable.

If the open-loop system is unstable or contains integration modes, the objective function of the IHMPC considered here must be slightly modified and other constraints should be included to guarantee that the objective function will be bounded. More details about these cases can be found in Martins and Odloak (2016).

In case of the implementation of the conventional finite horizon MPC the controller considered here solves the following problem:

$$
\begin{aligned}
\min _{\Delta u_{k}, y_{s p, k},} V_{k} & =\sum_{j=0}^{p}\left\|y(k+j \mid k)-y_{s p, k}\right\|_{Q_{y}}^{2}+ \\
& +\sum_{j=0}^{m-1}\left\|u(k+j \mid k)-u_{\text {des }}\right\|_{Q_{u}}^{2}+ \\
& +\sum_{j=0}^{m-1}\|\Delta u(k+j \mid k)\|_{R}^{2}
\end{aligned}
$$

subject to (7), (8), (9) and $y_{s p, k}=y_{\text {des }}$ for the outputs with optimizing targets.

In the problem defined in (13), $p$ is the output prediction horizon and one should observe that constraints (10) and (11) are not included in the conventional finite horizon MPC formulation. The inclusion of these constraints and the heavy penalization in (6) of the slack variables that are inserted in (10) and (11) raise the possibility of a strong interaction between the IHMPC layer and the target calculation layer. This point should be observed in the practical experiments performed here. Since the steady-state constraints are not present in the conventional controller, a lower 
level of interaction between the two layers would be expected.

To represent the output predictions along the output horizon in terms of the inputs along the control horizon, a dynamic model in the incremental form (Maciejowski, 2002) is adopted. This model is represented as follows:

$$
\begin{aligned}
& \mathrm{x}(\mathrm{k}+1)=\mathrm{Ax}(\mathrm{k})+\mathrm{B} \Delta \mathrm{u}(\mathrm{k}) \\
& \mathrm{y}(\mathrm{k})=\mathrm{Cx}(\mathrm{k})
\end{aligned}
$$

The advantage of the model defined in (14) is that any steady-state corresponds to an operating point where $\Delta u(k)=0$ and we do not need to know the explicit value of $u$ at the steady-state corresponding to a particular output set-point.

For the crude unit considered in this work, a transfer function model obtained from plant step tests is available (see Yamashita et al., 2016). To convert the transfer function model to the state space form represented in (14), one can consider the method proposed in Santoro and Odloak (2012). For this purpose, assume that the multivariable system has $n u$ inputs and $n y$ outputs and for each pair $\left(y_{i}, u_{j}\right)$, there is a transfer function of the form

$$
G_{i, j}(s)=\frac{b_{i, j, 0}+b_{i, j, 1} s+\ldots+b_{i, j, n b} s^{n b}}{\left(s-r_{i, j, 1}\right)\left(s-r_{i, j, 2}\right) \ldots\left(s-r_{i, j, n a}\right)} e^{-\theta_{i, j} s}
$$

Then, the step response of the above transfer function can be developed as follows:

$$
\begin{aligned}
S_{i, j}(s) & =\frac{G_{i, j}(s)}{s}=\frac{d_{i, j}^{0}}{s} e^{-\theta_{i, j} s}+ \\
& +\frac{d_{i, j, 1}^{d}}{s-r_{i, j, 1}} e^{-\theta_{i, j} s}+\ldots+\frac{d_{i, j, n a}^{d}}{s-r_{i, j, n a}} e^{-\theta_{i, j} s}
\end{aligned}
$$

Since the parameters $b_{i, j, l}, r_{i, j, l}$ and the time delay $\theta_{i, j}$ are assumed to be the coefficients $d^{0}{ }_{i, j}$ and $d^{\mathrm{d}}{ }_{i, j, l}$ can be obtained from the partial fraction expansion of $\left[G_{i, j}(s)\right] / s$.

Assuming that $\Delta t$ is the sampling time, (16) is equivalent to:

$\mathrm{S}_{\mathrm{i}, \mathrm{j}}(\mathrm{k} \Delta \mathrm{t})=0$, if $\mathrm{k} \Delta \mathrm{t} \leq \theta_{\mathrm{i}, \mathrm{j}}$

and:

$S_{i, j}(k \Delta t)=d_{i, j}^{0}+d_{i, j, 1}^{d} e^{r_{i, j,} k \Delta t-\theta_{i, j}}+\ldots+d_{i, j, n a}^{d} e^{r_{i, j, n a} k \Delta t-\theta_{i, j}}$ if $k \Delta t>\theta_{i, j}$

Then, the state vector of the model represented in (14) that is equivalent to the step response model represented above can be written as follows:

$$
\mathrm{x}(\mathrm{k})=\left[\begin{array}{c}
\mathrm{x}^{\mathrm{s}}(\mathrm{k}) \\
\mathrm{x}^{\mathrm{d}}(\mathrm{k}) \\
\mathrm{z}_{1}(\mathrm{k}) \\
\mathrm{z}_{2}(\mathrm{k}) \\
\vdots \\
\mathrm{z}_{\theta_{\max }}(\mathrm{k})
\end{array}\right]
$$

$x^{S} \in \mathfrak{R}^{\text {ny }} ; x^{d} \in C^{\text {ny.nu.na. }} ; z_{1}, \ldots, z_{\theta_{\max }} \in \mathfrak{R}^{\text {nu. }} ; x \in C^{n x} ; n x=$ $n y+n d+\theta_{\max } n u ; n d=n y . n u . n a, \theta_{\max }$ is the largest time delay between any input and any output.

With the state vector defined above, the state matrices of the model defined in (14) can be written as follows:

$\mathrm{A}=\left[\begin{array}{ccccccc}\mathrm{I}_{\mathrm{ny}} & 0 & \mathrm{~B}_{1}^{\mathrm{s}} & \mathrm{B}_{2}^{\mathrm{s}} & \cdots & \mathrm{B}_{\theta_{\max }-1}^{\mathrm{s}} & \mathrm{B}_{\theta_{\max }^{\mathrm{s}}}^{\mathrm{s}} \\ 0 & \mathrm{~F} & \mathrm{~B}_{1}^{\mathrm{d}} & \mathrm{B}_{2}^{\mathrm{d}} & \cdots & \mathrm{B}_{\theta_{\max }-1}^{\mathrm{d}} & \mathrm{B}_{\theta_{\max }}^{\mathrm{d}} \\ 0 & 0 & 0 & 0 & \cdots & 0 & 0 \\ 0 & 0 & \mathrm{I}_{\mathrm{nu}} & 0 & \cdots & 0 & 0 \\ \vdots & \vdots & \vdots & \ddots & \cdots & \vdots & \vdots \\ 0 & 0 & 0 & 0 & \cdots & \mathrm{I}_{\mathrm{nu}} & 0\end{array}\right]$

$\mathrm{B}=\left[\begin{array}{c}\mathrm{B}_{0}^{\mathrm{s}} \\ \mathrm{B}_{0}^{\mathrm{d}} \\ \mathrm{I}_{\mathrm{nu}} \\ 0 \\ \vdots \\ 0\end{array}\right]$

$\mathrm{C}=\left[\begin{array}{llllll}\mathrm{I}_{\text {ny }} & \Psi & 0 & 0 & \cdots & 0\end{array}\right]$

It can be shown that, in the state vector defined in (18), component $x^{S}(k)$ corresponds to the integrating states introduced into the model through the adopted incremental form of the input. It is easy to show that $x^{S}(k)$ is equal to the predicted output at steady state. This means that $y(k+\infty \mid k-1)=x^{S}(k)$, which is an interesting property of the model formulation considered here. The state component $x^{d}(k)$ corresponds to the stable modes of the original system, the state components $z_{1}$, $\ldots, z_{\theta_{\max }}$ store the last $\theta_{\max }$ control actions implemented in the true plant and $y(k)$ is the measured output.

If the stable poles of the system are non-repeated, matrix $F$ can be represented as follows:

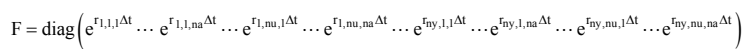

$\mathrm{F} \in \mathrm{C}^{\mathrm{nd} \times \mathrm{nd}}$ 
Matrices $B_{l}^{S}$ with $l=1, \ldots, \theta_{\max }$ can be computed as follows:

- If $1 \neq \theta_{i,}$, then $B_{l}^{S}=0$

- If $1=\theta_{i, j}$, then $\left[B_{l}^{S}\right]_{i, j}=\mathrm{d}^{0}{ }_{i, j}$

Matrices $B_{l}^{d}$ with $l \stackrel{l, j}{=} 1, \ldots, \theta_{\max }$ can be obtained as follows. If there are no dead times $(l=0)$, then $B_{0}{ }^{d}=$ $D^{d} F N$, where matrices $D^{d}$ and $N$ are defined as follows:

$D^{d}=\operatorname{diag}\left(d_{1,1,1}^{d} \cdots d_{1,1, n a}^{d} \cdots d_{1, n u, 1}^{d} \cdots d_{1, n u, n a}^{d} \cdots d_{n y, 1,1}^{d} \cdots d_{n y, 1, n a}^{d} \cdots d_{n y, n u, 1}^{d} \cdots d_{n y, n u, n a}^{d}\right)$

$\mathrm{D}^{\mathrm{d}} \in \mathrm{C}^{\mathrm{nd} \times \mathrm{nd}}$

$\left.\mathrm{N}=\left[\begin{array}{c}\mathrm{J} \\ \mathrm{J} \\ \vdots \\ \mathrm{J}\end{array}\right]\right\}$ ny, $\mathrm{N} \in \mathfrak{R}^{\mathrm{nd} \times \mathrm{nu}}$

$\mathrm{J}=\left[\begin{array}{cccc}1 & 0 & \cdots & 0 \\ \vdots & \vdots & \ddots & \vdots \\ 1 & 0 & \cdots & 0 \\ & & \ddots & \\ 0 & 0 & \cdots & 1 \\ \vdots & \vdots & \ddots & \vdots \\ 0 & 0 & \cdots & 1\end{array}\right], \mathrm{J} \in \mathfrak{R}^{\text {nu naxnu }}$

Alternatively, if $l \neq 0$, then each matrix $B_{l}^{d}$ would be a copy of $D^{d} F N$ but those elements corresponding to transfer functions with dead time different from $l$ are replaced with zeros. by:

Also, matrix $\Psi$, which appears in matrix $C$ is given

$\Psi=\left[\begin{array}{lll}\Phi & & 0 \\ & \ddots & \\ 0 & & \Phi\end{array}\right]$
$\Psi \in \mathfrak{R}^{\text {ny×nd }}$

$\Phi=\left[\begin{array}{llll}1 & 1 & \cdots & 1\end{array}\right]$

$\Phi \in \mathfrak{R}^{\text {nu na }}$

\section{THE MPC OF THE CRUDE DISTILLATION UNIT OF THE CAPUAVA REFINERY (BRAZIL)}

To implement the optimum operating point defined by the RTO layer of the industrial CDU system, the MPC (either infinite horizon or conventional) is built with 10 controlled outputs and 8 manipulated inputs. Table 1 shows the definitions of the controlled outputs, and their control zones that were adopted in the first practical case where the IHMPC is considered. Analogously, Table 2 shows the definitions of the manipulated inputs, their maximum and minimum bounds and the move bounds considered in these experiments.

Three operating scenarios were considered and the values of the outputs and inputs were collected from the Process Data Base of the Capuava Refinery. The first operating scenario (defined as Case I) considers the behavior of the CDU with the IHMPC and a particular set of tuning parameters for the target calculation layer. These parameters are the following:

$\mathrm{W}_{\mathrm{y}}=\operatorname{diag}\left(\begin{array}{llllllllll}1 & 0 & 0 & 0 & 0 & 0 & 0 & 0 & 0 & 0\end{array}\right.$,

$\mathrm{W}_{\mathrm{u}}=\operatorname{diag}\left(\begin{array}{llllllll}100 & 1 & 0 & 1 & 1 & 1 & 1 & 15000\end{array}\right)$

$\mathrm{W}_{2}=\operatorname{diag}\left(\begin{array}{llllllll}45 & 60 & 100 & 150 & 1.5 & 1.3 & 1 & 4200\end{array}\right)$

$\mathrm{W}_{3}=\operatorname{diag}\left(\begin{array}{llllllllll}1 & 1 & 1 & 1 & 1 & 1 & 1 & 1 & 1 & 1\end{array}\right) \times 10^{6}$

Observing these parameters, it is clear that, except input $u_{3}$ (stripping steam to N-507), all the inputs have targets that are defined by the RTO layer. The

Table 1. Output variables and control zones (IHMPC).

\begin{tabular}{lcccccc}
\hline & Variable definition & Unit & $\begin{array}{c}\text { Min } \\
\text { (Case I) }\end{array}$ & $\begin{array}{c}\text { Max } \\
\text { (Case I) }\end{array}$ & $\begin{array}{c}\text { Min } \\
\text { (Case III) }\end{array}$ & $\begin{array}{c}\text { Max } \\
\text { (Case III) }\end{array}$ \\
\hline$y_{1}$ & N-507 stripping steam/crude & $\mathrm{kg}^{3} / \mathrm{m}^{3}$ & 3 & 8 & 1.7 & 8 \\
$y_{2}$ & Heavy naphtha flow rate & $\mathrm{m}^{3 / \mathrm{d}}$ & 150 & 450 & 150 & 400 \\
$y_{3}$ & N-506 reflux flow rate & $\mathrm{m}^{3 / \mathrm{d}}$ & 800 & 1200 & 1000 & 1300 \\
$y_{4}$ & Kerosene withdraw temperature & ${ }^{\circ} \mathrm{C}$ & 180 & 193 & 180 & 193 \\
$y_{5}$ & Diesel ASTM D-86 95\% & ${ }^{\circ} \mathrm{C}$ & 365 & 371 & 365 & 370 \\
$y_{6}$ & Diesel flash point & ${ }^{\circ} \mathrm{C}$ & 25 & 69 & 25 & 69 \\
$y_{7}$ & Light naphtha ASTM D-86 end point & ${ }^{\circ} \mathrm{C}$ & 172.5 & 185 & 175 & 185 \\
$y_{8}$ & N-507 reflux flow rate & $\mathrm{m}^{3 / \mathrm{d}}$ & 900 & 1450 & 900 & 1450 \\
$y_{9}$ & Light naphtha flow rate & $\mathrm{m}^{3 / \mathrm{d}}$ & 900 & 1400 & 950 & 1450 \\
$y_{10}$ & L-506 heat duty & $\mathrm{Gcal} / \mathrm{h}$ & 8 & 20.5 & 8 & 20.5 \\
\hline
\end{tabular}


Table 2. Input variables, bounds and maximum increment values (IHMPC).

\begin{tabular}{|c|c|c|c|c|c|c|c|}
\hline & Variable definition & Unit & $\begin{array}{c}\text { Min } \\
\text { (Case I) }\end{array}$ & $\begin{array}{c}\text { Max } \\
\text { (Case I) }\end{array}$ & $\begin{array}{c}\text { Min } \\
\text { (Case III) }\end{array}$ & $\begin{array}{c}\text { Max } \\
\text { (Case III) }\end{array}$ & $\Delta u_{\max }$ \\
\hline$u_{1}$ & Crude feed flow rate & $\mathrm{m}^{3 / \mathrm{d}}$ & 9299 & 9300 & 9049 & 9050 & 20.0 \\
\hline$u_{2}$ & N-507 top temperature & ${ }^{\circ} \mathrm{C}$ & 126 & 128 & 128 & 130 & 0.1 \\
\hline$u_{3}$ & N-507 stripping steam & $\mathrm{t} / \mathrm{h}$ & 1.2 & 1.8 & 1.8 & 2.2 & 0.03 \\
\hline$u_{4}$ & $\mathrm{~N}-506$ top temperature & ${ }^{\circ} \mathrm{C}$ & 118 & 119 & 115 & 116 & 0.05 \\
\hline$u_{5}$ & Heavy diesel reflux & $\mathrm{m}^{3 / \mathrm{d}}$ & 550 & 2000 & 550 & 2000 & 10.0 \\
\hline$u_{6}$ & Diesel pumparound & $\mathrm{m}^{3 /} / \mathrm{d}$ & 3800 & 6500 & 4400 & 7000 & 8.0 \\
\hline$u_{7}$ & Kerosene outlet flow rate & $\mathrm{m}^{3 /} / \mathrm{d}$ & 900 & 1000 & 950 & 1100 & 6.0 \\
\hline$u_{8}$ & L-506 outlet temperature & ${ }^{\circ} \mathrm{C}$ & 363 & 367 & 370 & 371 & 0.07 \\
\hline
\end{tabular}

remaining degree of freedom is allocated to output $y_{1}$, which has an optimizing target instead of a control zone. The definition of which inputs and outputs should have targets was made in a previous study and is not included here.

Some values of $W_{u}$ call our attention. The weight corresponding to input $u_{8}$ is very large $\left(W_{u}(8,8)=\right.$ 15000), which means that the target of the outlet temperature of the furnace should be prioritized with respect to all other input targets to follow the optimum value $\left(u_{R T O, 8}\right)$ defined by the RTO layer. The crude feed flow rate $\left(u_{1}\right)$ has the second largest value of $W_{u}$, and is prioritized to follow the target defined by the RTO layer. Also, the large value of the parameter $W_{2}$ corresponding to the furnace outlet temperature $\left(W_{2}(8,8)=4200\right)$ means that this manipulated variable should be moved very smoothly when the optimum value is approached.

From Table 2, one observes that the range of $u_{1}$ is very narrow (only $1 \mathrm{~m}^{3} / \mathrm{d}$ ), which means that the crude oil flow rate is nearly fixed and is not a degree of freedom in the optimization and control of the crude distillation unit.

In the first operating scenario considered here, the RTO layer starts producing an optimum operating point that corresponds to the following variables $y_{R T O, 1}=5.7$ $\mathrm{kg} / \mathrm{m}^{3}, u_{R T O, 1}=9300 \mathrm{~m}^{3} / \mathrm{d}, u_{R T O, 2}=128 \mathrm{C}, u_{R T O, 4}=119 \mathrm{C}$, $u_{R T O, 5}=1350 \mathrm{~m}^{3} / \mathrm{d}, u_{R T O, 6}=4856 \mathrm{~m}^{3} / \mathrm{d}, u_{R T O, 7}=1000 \mathrm{~m}^{3} / \mathrm{d}$ and $u_{\text {RTO. }}=363 \mathrm{C}$. Observe that the optimum point is defined by the values of 8 variables ( 1 output and 7 inputs), which is the number of degrees of freedom of the crude distillation unit studied here.

With the values of $y_{R T O}$ and $u_{R T O}$ defined by the RTO layer, the last implemented input $u(k-1)$, the predicted output at steady-state $y(k+\infty \mid k-1)$ and the parameters defined in (20), the problem defined in (1) to (5) was solved to define the values of $y_{\text {des }}$ and $u_{\text {des }}$ that are passed to the IHMPC layer where the problem defined through equations (6) to (12) is solved.

Inside the MPC the inputs and outputs are normalized considering the following factors:

$$
\begin{aligned}
& E_{u}=\left[\begin{array}{llllllll}
9000 & 200 & 5 & 200 & 2500 & 8500 & 1800 & 500
\end{array}\right] \\
& \mathrm{E}_{\mathrm{y}}=\left[\begin{array}{llllllllll}
14.1 & 2447 & 5743 & 179 & 477 & 51 & 10 & 530 & 471 & 1.8
\end{array}\right]
\end{aligned}
$$

The normalization of the variables inside the controller may be interesting for a better numerical conditioning of the optimization problem that defines the controller and to facilitate the controller tuning.

Then, considering the normalized variables and adopting the tuning method of Yamashita et al. (2016), the tuning parameters of the IHMPC defined in (6) to (12) are the following:

Control horizon $m=4$, sampling period $T=1 \mathrm{~min}$

$$
\begin{aligned}
& \mathrm{Q}_{\mathrm{y}}=\operatorname{diag}\left(\begin{array}{llllllllll}
5 & 2 & 1 & 3 & 50 & 5 & 5 & 7 & 10 & 20
\end{array}\right) \\
& \mathrm{Q}_{\mathrm{u}}=\operatorname{diag}\left(\begin{array}{llllllll}
1 & 1 & 0 & 1 & 1 & 1 & 1 & 1
\end{array}\right) \\
& \mathrm{R}=\operatorname{diag}\left(\begin{array}{llllllll}
0.1 & 6 & 3 & 5 & 1 & 6.6 & 1 & 142
\end{array}\right) \\
& \mathrm{S}_{\mathrm{y}}=\operatorname{diag}\left(\begin{array}{llllllllll}
1 & 1 & 1 & 1 & 1 & 1 & 1 & 1 & 1 & 1
\end{array}\right) \times 10^{6} \\
& \mathrm{~S}_{\mathrm{u}}=\operatorname{diag}\left(\begin{array}{llllllll}
1 & 1 & 1 & 1 & 1 & 1 & 1 & 1
\end{array}\right) \times 10^{6}
\end{aligned}
$$

From the above set of tuning parameters, we observe that the elements of $Q_{u}$ that penalize the distance between the input value and the desired value are the same for all the normalized input variables. The only exception is $Q_{u}(3,3)=0$ because $u_{3}$ has no optimizating target. Also, similarly to the target calculation layer, in the IHMPC layer, any movement in the furnace outlet temperature $\left(u_{8}\right)$ is heavily penalized through $R(8,8)$.

In the operating window captured here the CDU plant starts from the following initial operating point:

$y(k)=\left(\begin{array}{llllllllll}5.8 & 302 & 1104 & 182 & 370.9 & 33.8 & 172.3 & 1409 & 1237 & 15.7\end{array}\right)^{\mathrm{T}}$

$u(k)=\left(\begin{array}{llllllll}9300 & 128 & 1.8 & 119 & 1340 & 4860 & 997 & 363\end{array}\right)^{\mathrm{T}}$

Observe that this initial point is very close to the optimum operating point defined by the RTO layer. Figure 3 shows the controlled outputs of the crude distillation along a period of nearly 6 hours with the control system starting from the initial point defined above and trying to follow the RTO targets. The 

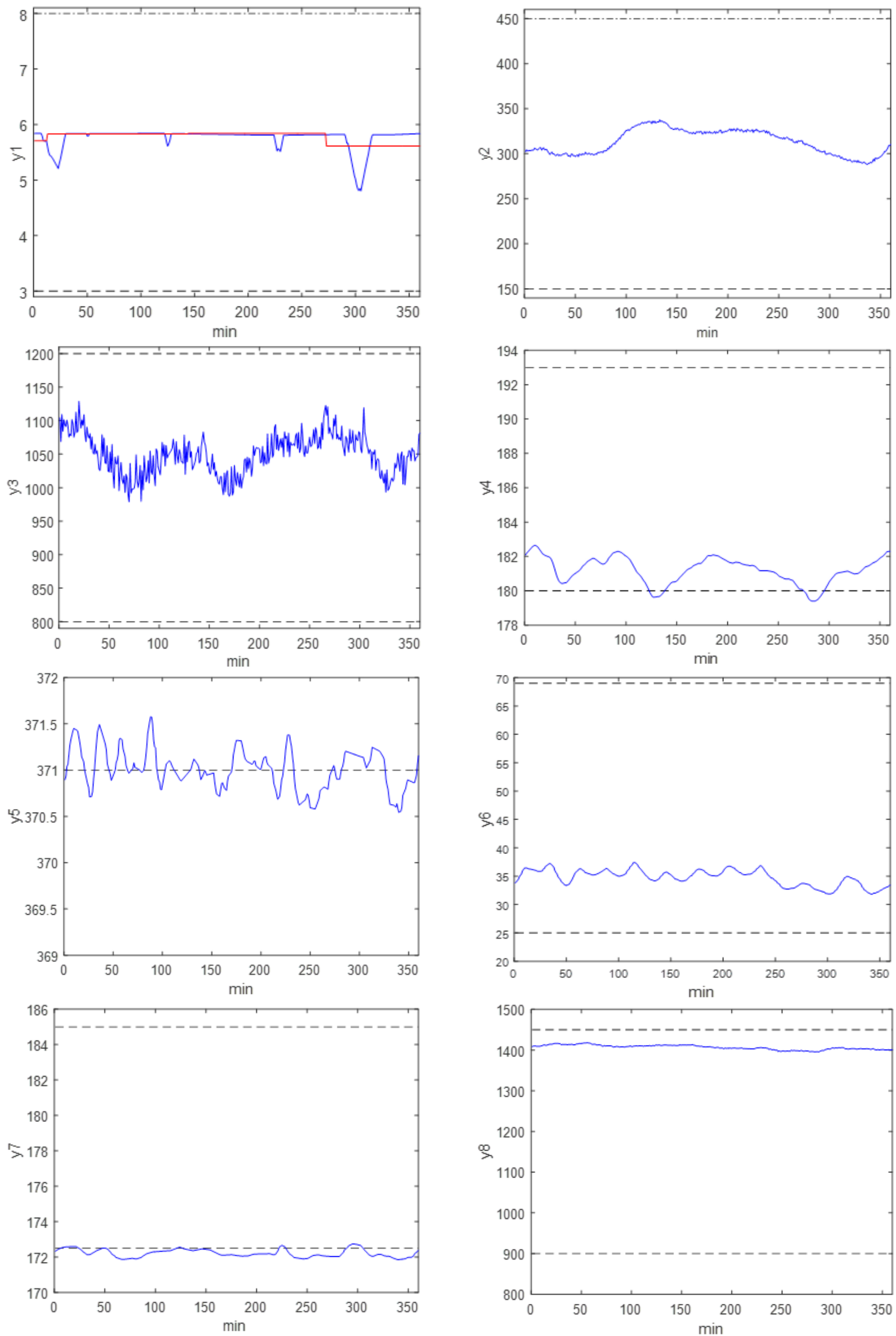

Continues on the next page 

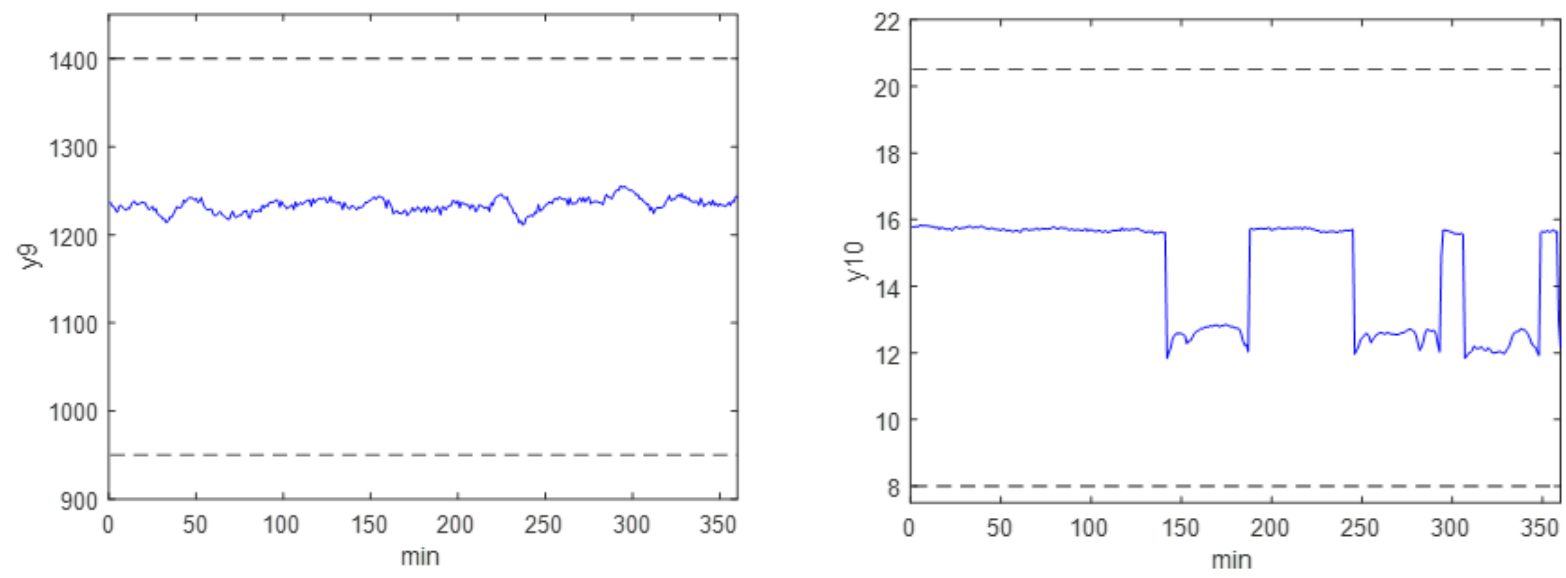

Figure 3. Outputs of the Crude Distillation Unit (IHMPC Case I),

corresponding inputs are represented in Figure 4 along the same period of time. These data were collected from the process data base that is connected to the Digital Control System of the CDU.

Table 3 presents the four optimum operating points computed by the RTO layer along the period of time considered in Case I. One can observe that these operating points only differ in the optimum values of stripping steam that is injected into the atmospheric column $\left(y_{1}\right)$, the diesel reflux flow rate $\left(u_{5}\right)$ and the
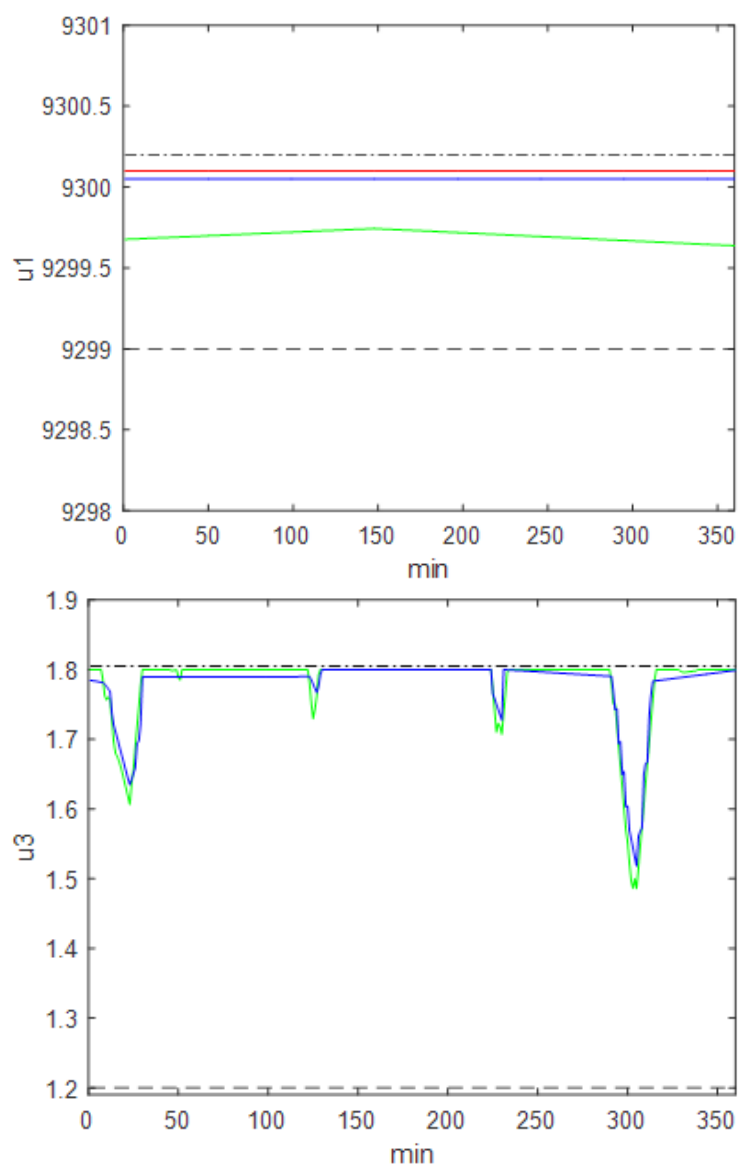

diesel pumparound flow rate $(u)$. The optimum values of these variables are not at their bounds, while the remaining five other targets lay on the max or min bounds of the corresponding inputs. However, we observe that other outputs such as the Diesel ASTM D-86 95\% $\left(y_{5}\right)$ and the naphtha end point $\left(y_{7}\right)$ also lie at the bounds. This means that the RTO layer is really playing a minor part in optimization of the CDU, as the optimum operating point is basically defined by the constraints.
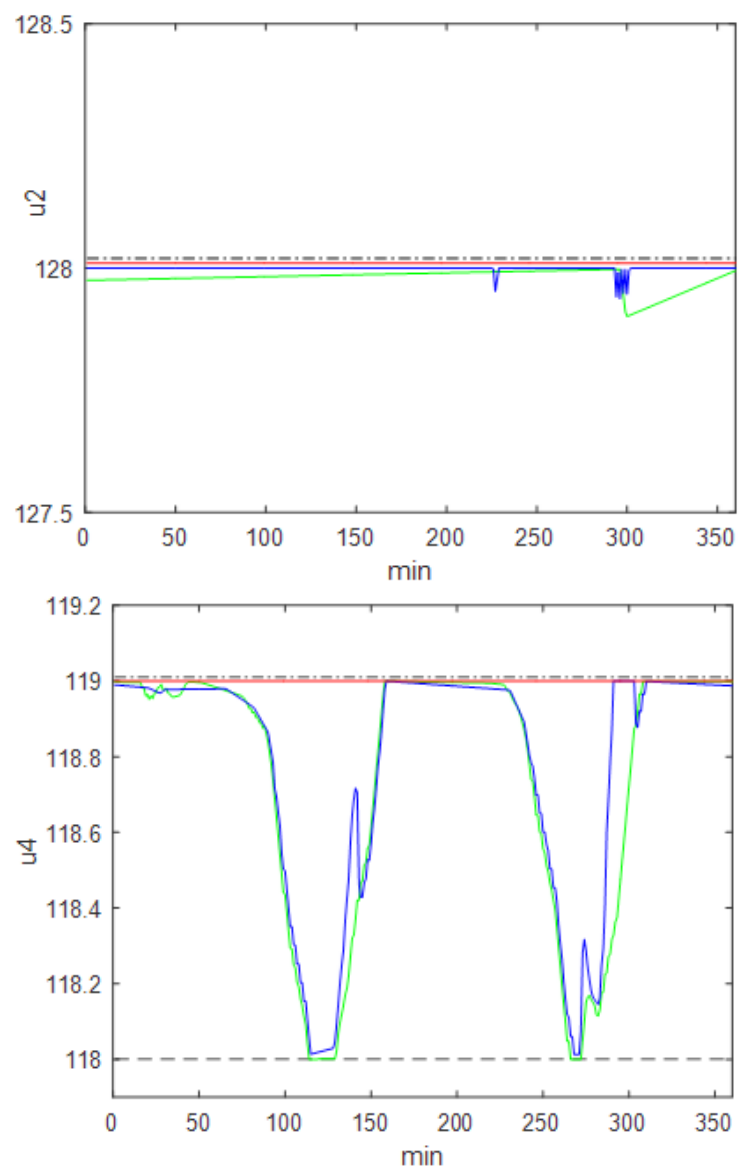

Continues on the next page 

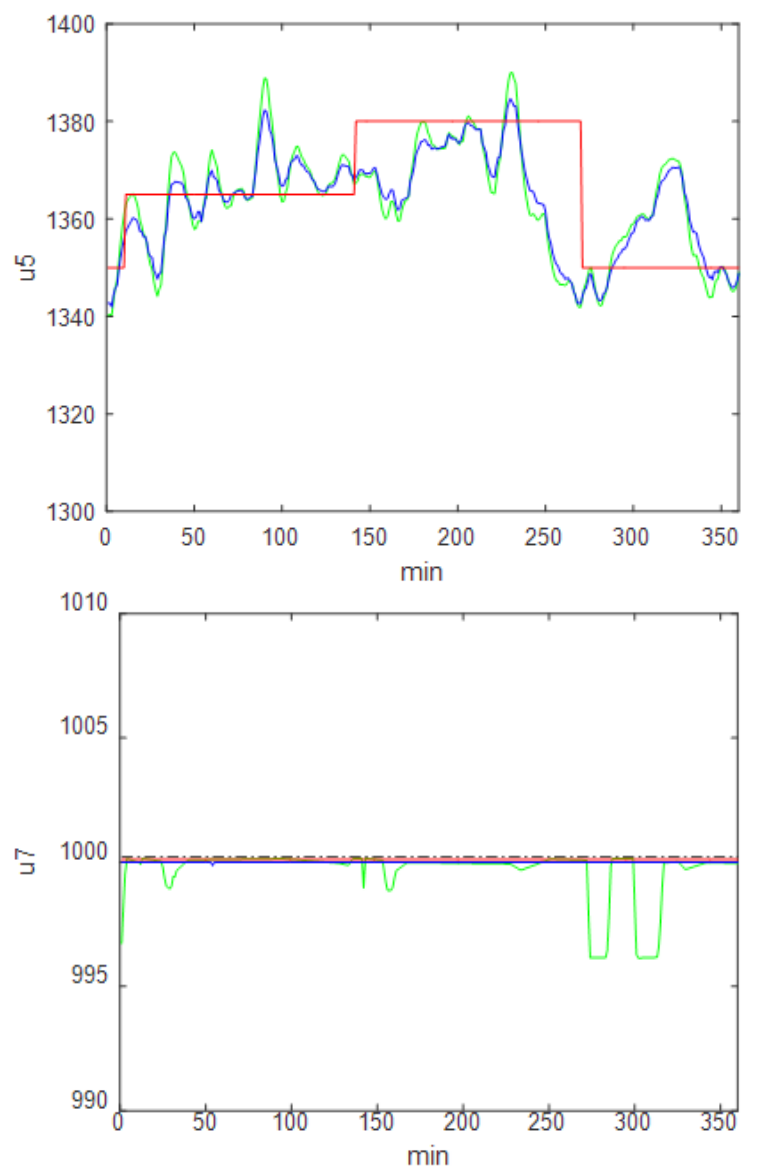
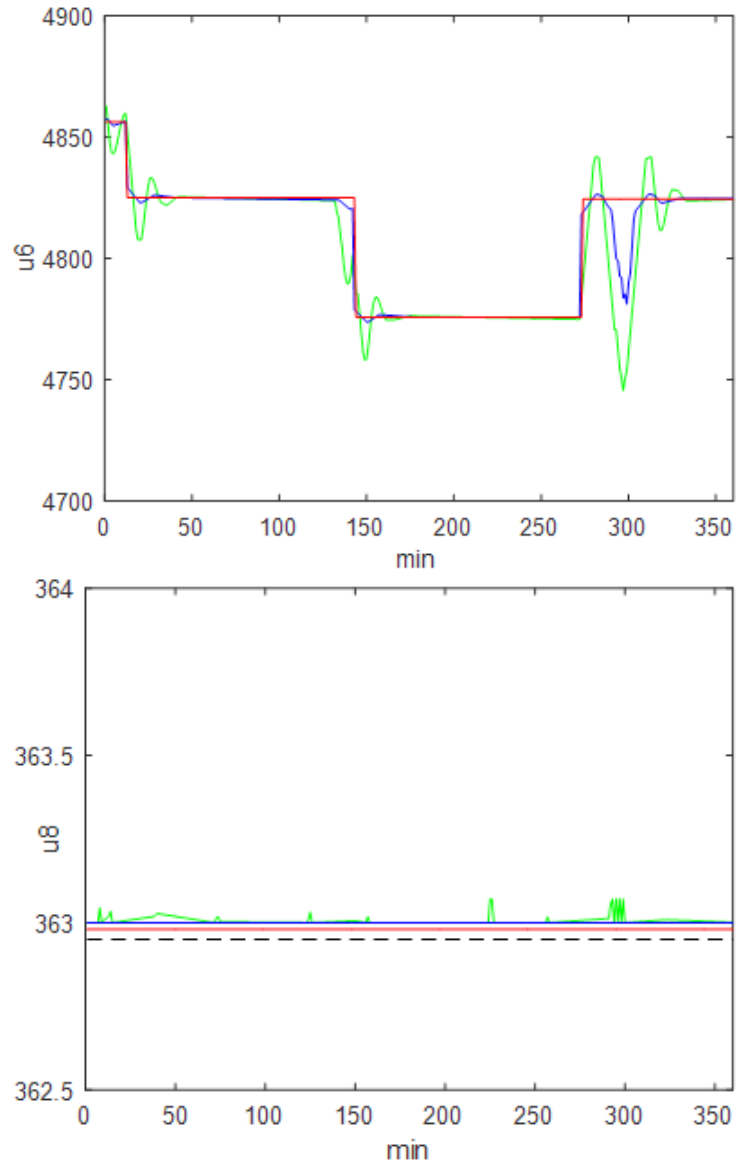

Figure 4. Inputs of the Crude Distillation Unit (IHMPC Case I).

Table 3. Optimum steady-states of the CDU in Case I.

\begin{tabular}{|c|c|c|c|c|c|c|c|c|}
\hline Time (min) & $y_{R T O, 1}$ & $u_{R T O, 1}$ & $u_{R T O, 2}$ & $u_{R T O, 4}$ & $u_{R T O, 5}$ & $u_{R T O, 6}$ & $u_{R T O, 7}$ & $U_{R T O, 8}$ \\
\hline 0 & 5.800 & 9300 & 128 & 119 & 1350 & 4856 & 1000 & 363 \\
\hline 12 & 5.828 & 9300 & 128 & 119 & 1365 & 4825 & 1000 & 363 \\
\hline 143 & 5.838 & 9300 & 128 & 119 & 1380 & 4775 & 1000 & 363 \\
\hline 272 & 5.611 & 9300 & 128 & 119 & 1350 & 4824 & 1000 & 363 \\
\hline
\end{tabular}

From Fig. 3 and Fig. 4, it can be observed that the IHMPC tends to follow most of the RTO targets of the variables listed in Table 3, particularly the targets of $y_{1}, u_{5}$ and $u_{6}$. Fig. 3 shows that outputs $y_{2}, y_{3}, y_{6}, y_{8}, y_{9}$ and $y_{10}$ remain inside their control zones and never get close to their bounds in this period of time. Output $y_{4}$ was kept inside its control zone, but eventually touched its minimum bound, and outputs $y_{5}$ and $y_{7}$ were kept at their maximum and minimum bounds, respectively, with acceptable variances.

Concerning the behavior of the other inputs of the CDU system, Fig. 4 shows that $u_{1}, u_{2}, u_{7}$ and $u_{8}$ follow the targets defined by the RTO layer satisfactorily. Since there is no RTO target for input $u_{3}$, this variable is mainly used for the control of output $y_{1}$. However, from Fig 4, one observes that, although $u_{R T O, 4}$ remained at its maximum bound along the whole time window of Case I, the value of $u_{\text {des, }}$ oscillated and was followed by $u_{4}$ that also oscillated. Based on the observation of other operating windows that were not included here, one concludes that $u$ does not stabilize and would tend to increase the oscillation amplitude if its operating range was enlarged. This behavior indicates that the integration approach adopted here is not nominally stable like the approach proposed in Alvarez \& Odloak, (2010). Their method includes additional constraints that are not present in the target calculation layer of the conventional MPC that was adopted in the control of the CDU system. As discussed in the previous section, the interaction is mainly associated with the adopted tuning of the target calculation layer, which results in a slow dynamics for the static layer and a consequent interaction between the target calculation layer and the IHMPC layer.

As commented before, the interaction between the Target Calculation layer and the IHMPC layer can be motivated by the inclusion of the constraints defined in equations (10) to (12) that force the objective function 
of the IHMPC to be bounded. Observe that the predicted output at steady-state $y(k+\infty \mid k)$ appears in eq. (10) of the dynamic problem and $y(k+\infty \mid k-1)$ appears in eq. (2) of the static problem that calculates the targets. One should also note that the slack $\delta_{y, k}$ is heavily penalized in the objective function of the IHMPC (eq. 6). This means that the controller pays great attention to the predicted steady-state of the output. The consequence is that, with the infinite horizon controller, the two layers can interact and produce instability in the presence of model uncertainty. Although it is not possible to reproduce the same scenario as the one considered in Case I, it would be interesting to include Case II to verify if the same sort of interaction was observed with the conventional finite horizon MPC that was used to control the CDU for several years before the implementation of the IHMPC.

To compare the performance of the IHMPC considered in Case I with the conventional MPC defined as Case II, one considers some plant results collected a few years before the implementation of the IHMPC. These results correspond to a case where the target calculation problem defined in equations (1) to (5) with the same tuning parameters as in Case I is solved and provides the targets to the conventional MPC defined in (13) with the same normalized variables as the IHMPC and the following tuning parameters:

Control horizon $m=4$; output horizon $p=90$; sampling period $T=1 \mathrm{~min}$.

$Q_{y}$ and $Q_{u}$ are the same as in Case I and

$$
\mathrm{R}=\operatorname{diag}\left(\begin{array}{llllllll}
0.1 & 6 & 3 & 5 & 0.15 & 4 & 1 & 20
\end{array}\right)
$$

Then, with the exception of weights $S_{y}$ and $S_{u}$ of the slack variables, which are not present in the finite horizon MPC, the remaining tuning parameters of the conventional MPC are not too different from the tuning parameters of the IHMPC of Case I. The input move penalization weights $R(5,5), R(6,6)$ and $R(8,8)$ are smaller for the MPC, indicating that the controller can take faster responses than the IHMPC.

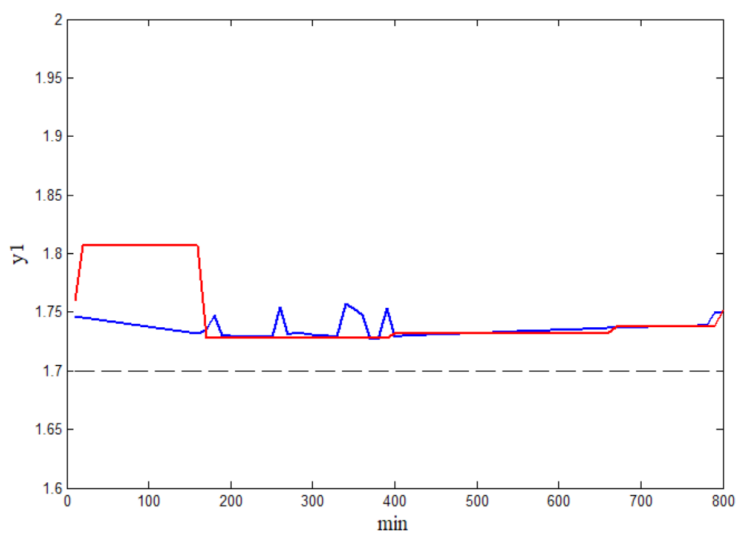

From Figures (5) and (6), one can note that the operating conditions corresponding to Case II are not close to the conditions of Case I. For instance, the crude flow rate in Case II is about $20 \%$ smaller than in Case I. Also, the naphtha produced at the top of the preflash column (N-507) in Case II is significantly lighter than in Case I (ASTM D-86 end point is about 15C smaller). This shows that the CDU studied here can face quite different scenarios, which may correspond to different dynamic models leading to a robustness problem related to the model uncertainty. This problem seems to be critical in the results reported in Case II. We observe that the operator has changed the bounds of outputs $y_{4}$ and $y_{5}$ and input $u_{6}$. Apparently, he is trying to force the CDU system to follow a more suitable pattern. The troubled operation is evidenced by the responses of input $u_{4}$ that is cycling as in Case I and input $u_{7}$, which is moved along all its operating range. From these results, we conclude that instability in the multilayer integration of RTO and IHMPC mainly results from the interaction between the static target calculation layer and the infinite horizon controller. The strong interaction can be attributed to constraints related to the predicted steady-state that are included in both layers. This conclusion is confirmed by simulation results, not included here, considering the ideal model case. These simulations show that IHMPC and the target calculation layer considered in this work can become unstable even when the model is perfect. The interaction can be minimized by a proper tuning of the static layer. An alternative to prevent this interaction is to adopt the method of Alvarez and Odloak (2010), where the target calculation layer and the IHMPC layer are modified in order to not disrupt other steady-state predictions. In the case of the finite horizon MPC, the instability seems to result from the larger sensitivity of the conventional controller to model uncertainty as the simulation of the ideal case shows no oscillation of the multilayer system with the finite horizon controller.

Apparently, the correct approach to integrate RTO and MPC in the CDU is to adopt a robust structure

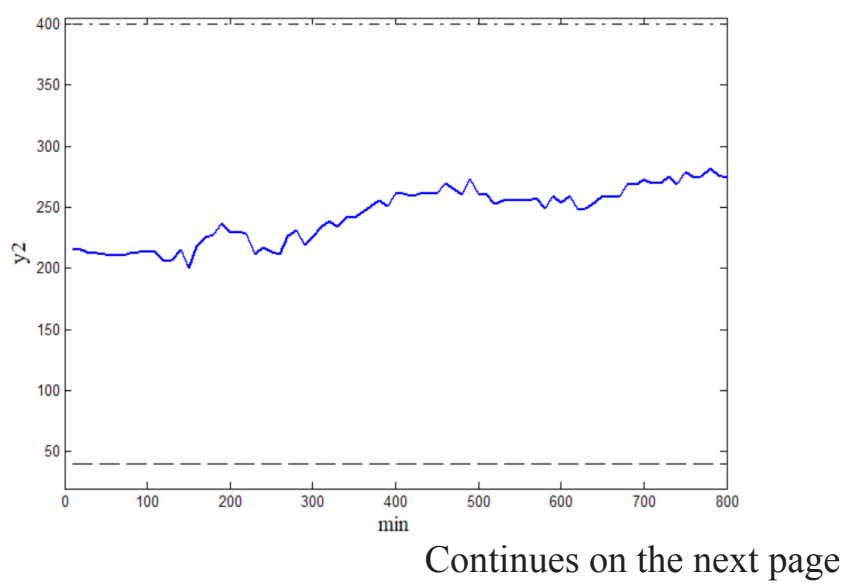



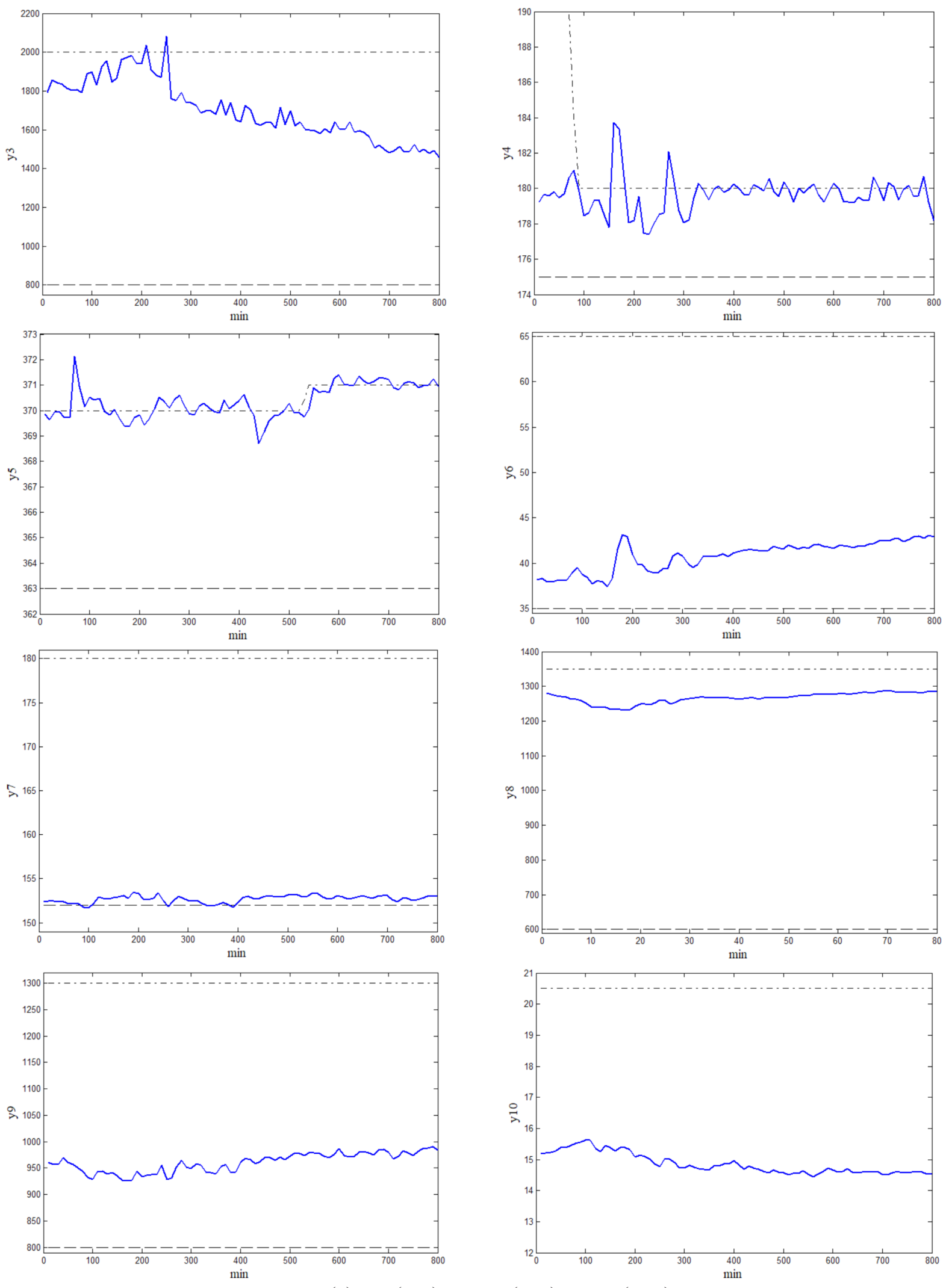

Figure 5. Outputs of the Crude Distillation Unit (MPC Case II),

such as the one proposed in Alvarez \& Odloak (2010). However, their approach is based on the multimodel representation of the process. This means that the process model needs to be identified at several operating points. The multimodel representation of the CDU is not available at this point, but will be the 

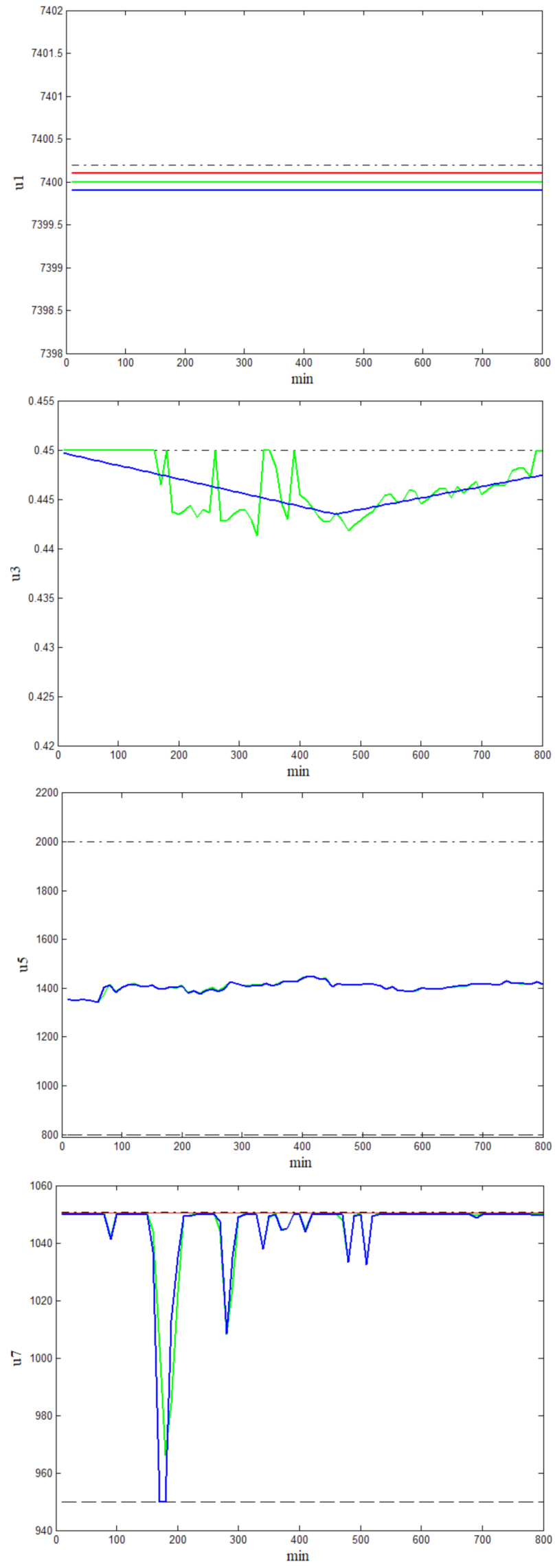
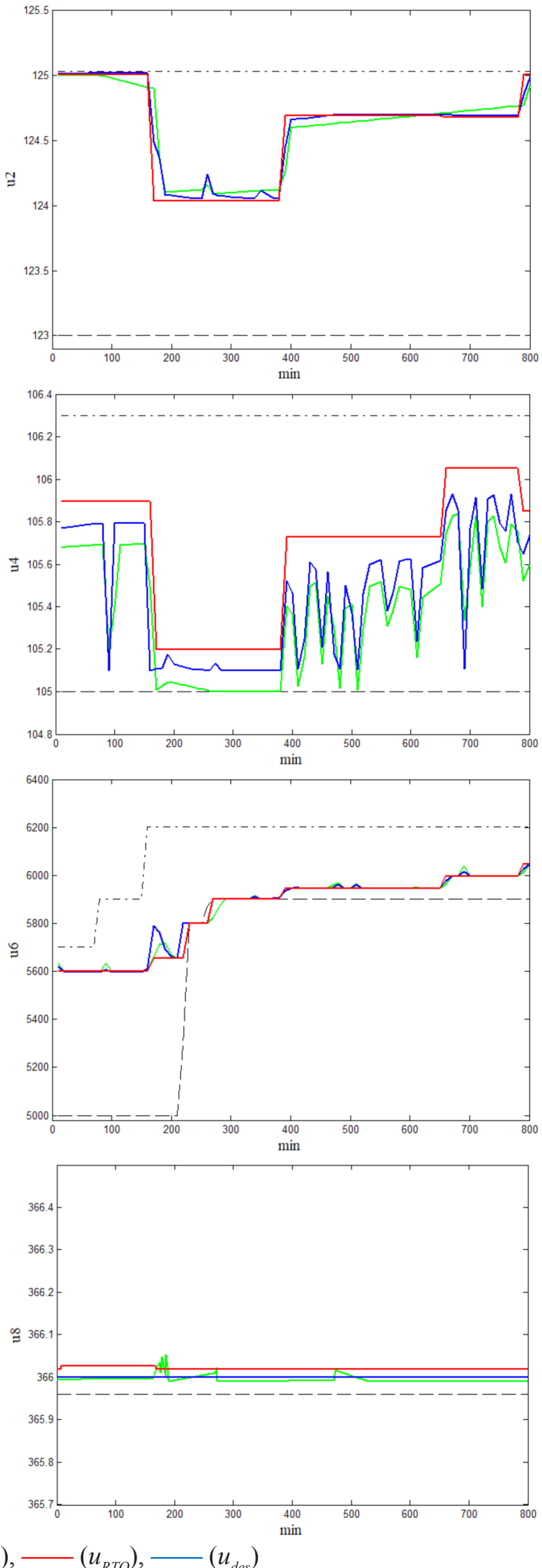

Figure 6. Inputs of the Crude Distillation Unit (MPC Case II) 
subject of a future research work. Another option to reduce the interaction between the two layers of the control structure is to retune the target calculation layer that in cases I and II prioritizes too heavily the feed flow rate $\left(u_{1}\right)$ and the oil heater outlet temperature $\left(u_{8}\right)$. In Case III, the IHMPC is implemented with a target calculation layer with new matrices $W_{y}$ and $W_{u}$ as follows:

$$
\begin{aligned}
& \mathrm{W}_{\mathrm{y}}=\operatorname{diag}\left(\begin{array}{llllllllll}
5 & 0 & 0 & 0 & 0 & 0 & 0 & 0 & 0 & 0
\end{array}\right) \\
& \mathrm{W}_{\mathrm{u}}=\operatorname{diag}\left(\begin{array}{llllllll}
300 & 20 & 0 & 50 & 5 & 20 & 20 & 1000
\end{array}\right)
\end{aligned}
$$

One can observe from (22) that, in Case III, a more balanced tuning was adopted as the difference between the elements of $W$, which is not as large as in cases I and II. The remaining tuning parameters $\left(\mathrm{W}_{2}\right.$ and $W_{3}$ ) were kept the same as in the previous cases. Also the tuning parameters defined in (21) for the IHMPC remained the same. As shown in Tables I and II, the ranges of the manipulated and controlled outputs were slightly different from the ranges of Case I. The new ranges were set by the operators to accommodate a different operating scenario.

The time window that characterizes Case III corresponds to a period of $8.3 \mathrm{~h}$ where the process variables were collected with a sampling time of 1 minute. Table 4, shows the three optimum operating points that were computed by the RTO layer along this period of time. As in Case I, one observes that these operating points are close to each other and show small differences in the values of $y_{\text {RTO, },}, u_{R T O, 2}, u_{R T O, 4}$, $u_{R T O, 5}, u_{R T O, 6}$ and $u_{R T O, 8}$. The other RTO targets remained in the bounds of the corresponding inputs.

Figure 7 shows that $y_{1}$ followed $y_{R T O, 1}$ very closely, while output $y_{5}$ was controlled at its maximum bound and $y_{7}$ was kept near to its minimum bound. The remaining outputs were kept inside their control zones.

Figure 8 shows that, except for input $u_{3}$, all the other inputs followed the targets $u_{\text {des }}$ that were computed in the Target Calculation Layer. These targets also

\begin{tabular}{|c|c|c|c|c|c|c|c|c|}
\hline Time (min) & $y_{R T O, 1}$ & $u_{R T O, 1}$ & $u_{R T O, 2}$ & $u_{R T O, 4}$ & $u_{R T O, 5}$ & $u_{R T O, 6}$ & $u_{R T O, 7}$ & $u_{R T O, 8}$ \\
\hline 0 & 6.07 & 9050 & 130 & 116 & 1820 & 6948 & 1100 & 370.8 \\
\hline 221 & 6.03 & 9050 & 130 & 115.6 & 1800 & 6995 & 1100 & 370 \\
\hline 362 & 6.06 & 9050 & 129.8 & 115 & 1780 & 7000 & 1100 & 370 \\
\hline
\end{tabular}

Table 4. Optimum steady-states of the CDU in Case III.
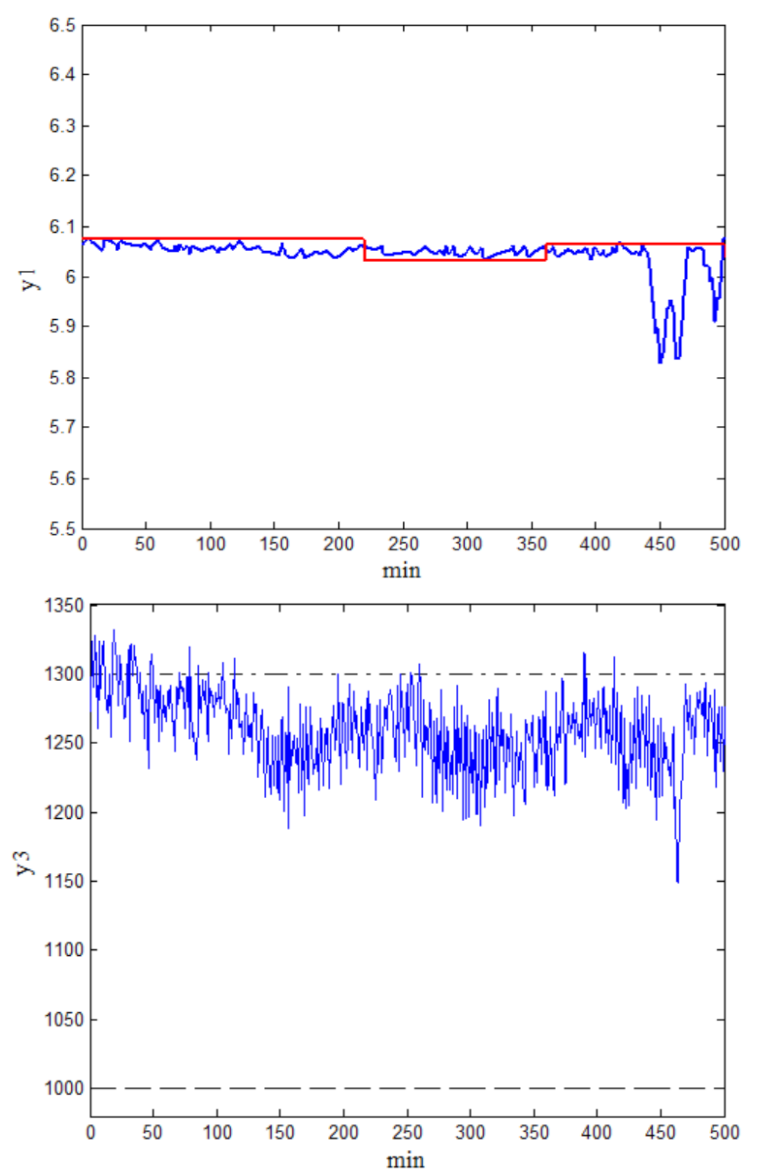
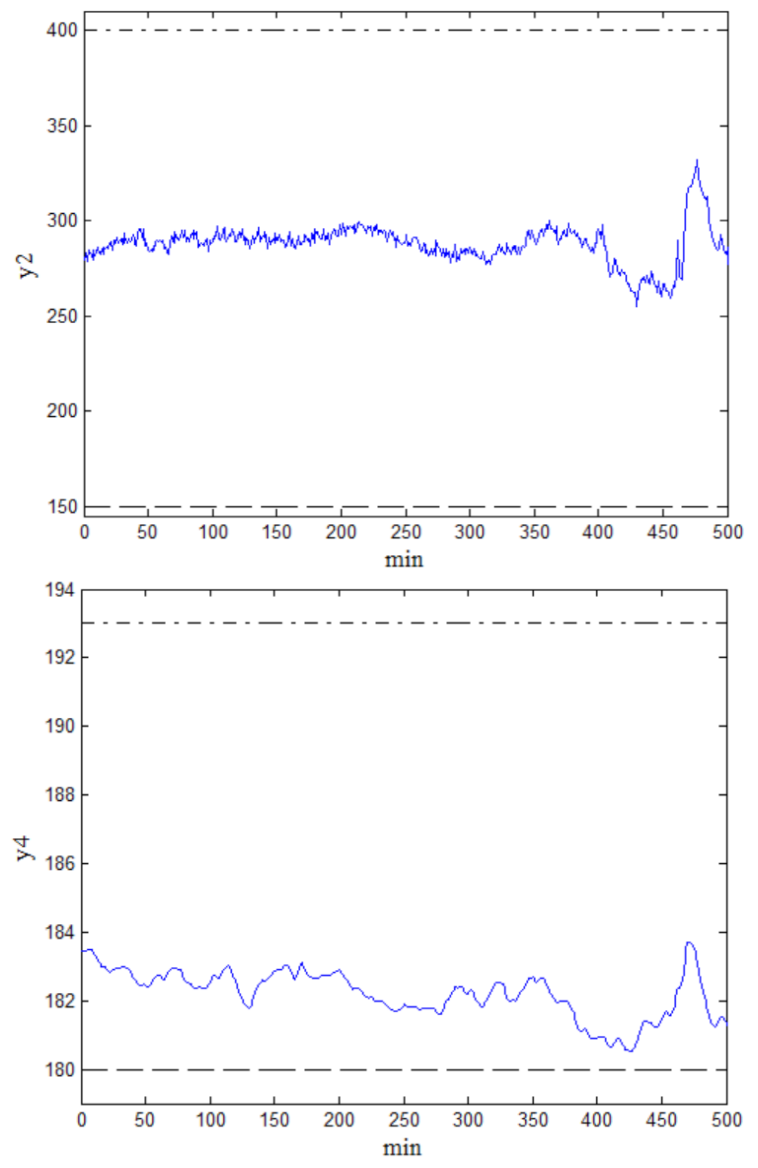

Continues on the next page 

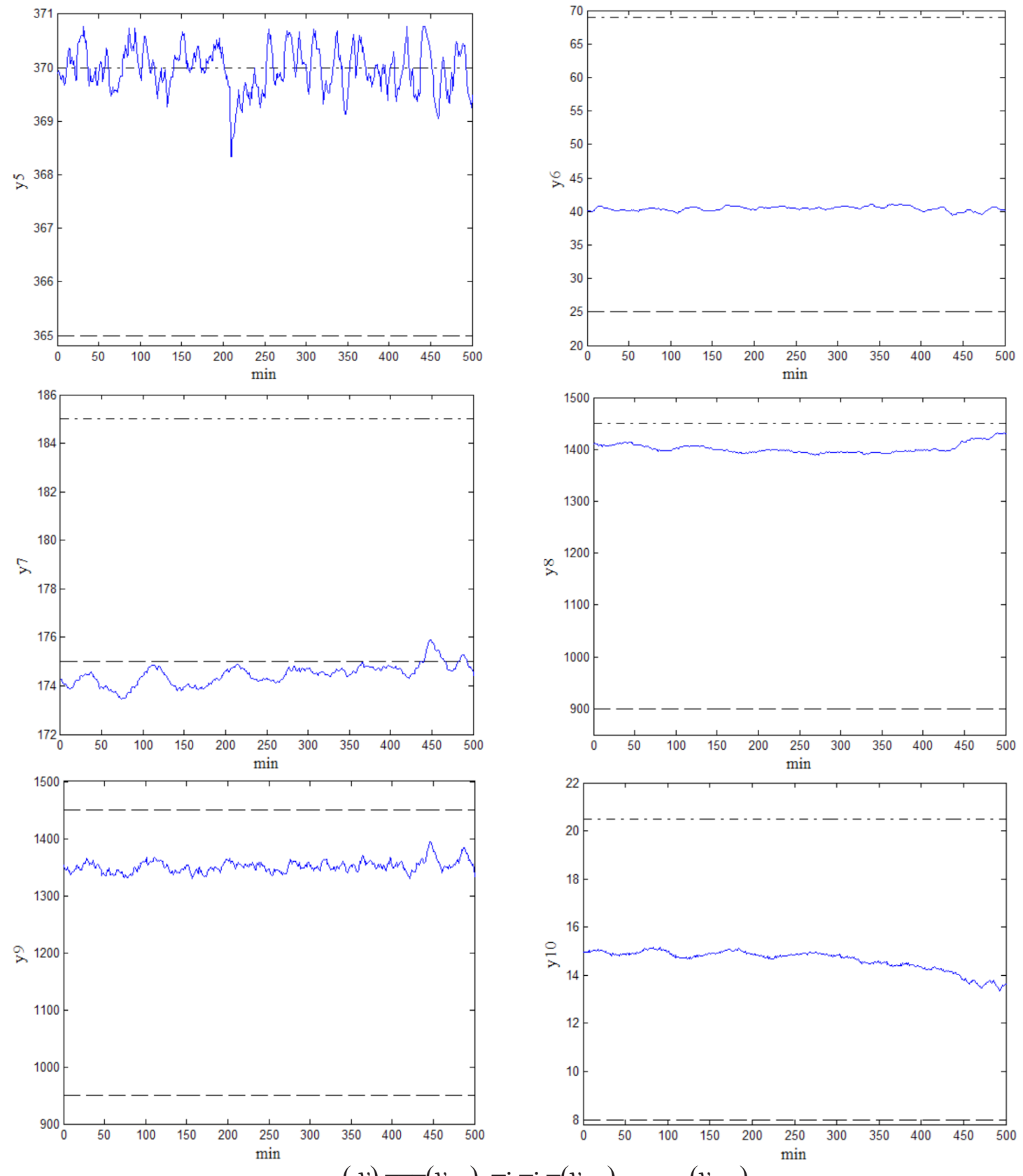

Figure 7. Outputs of the Crude Distillation Unit (Case III).
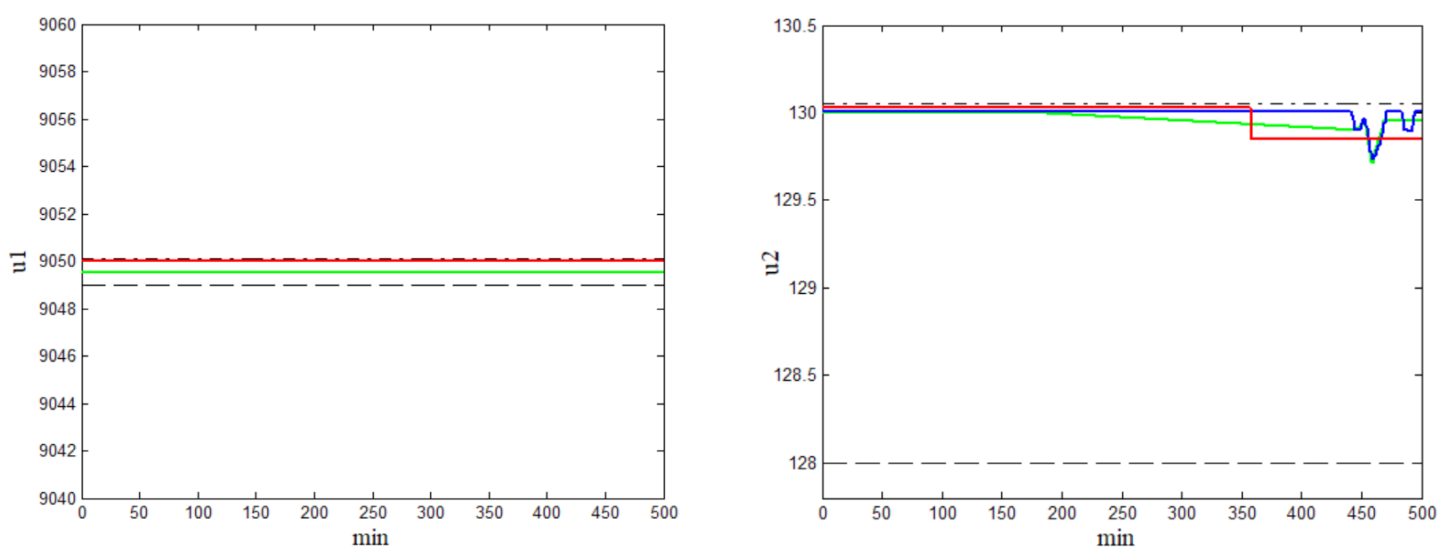

Continues on the next page 

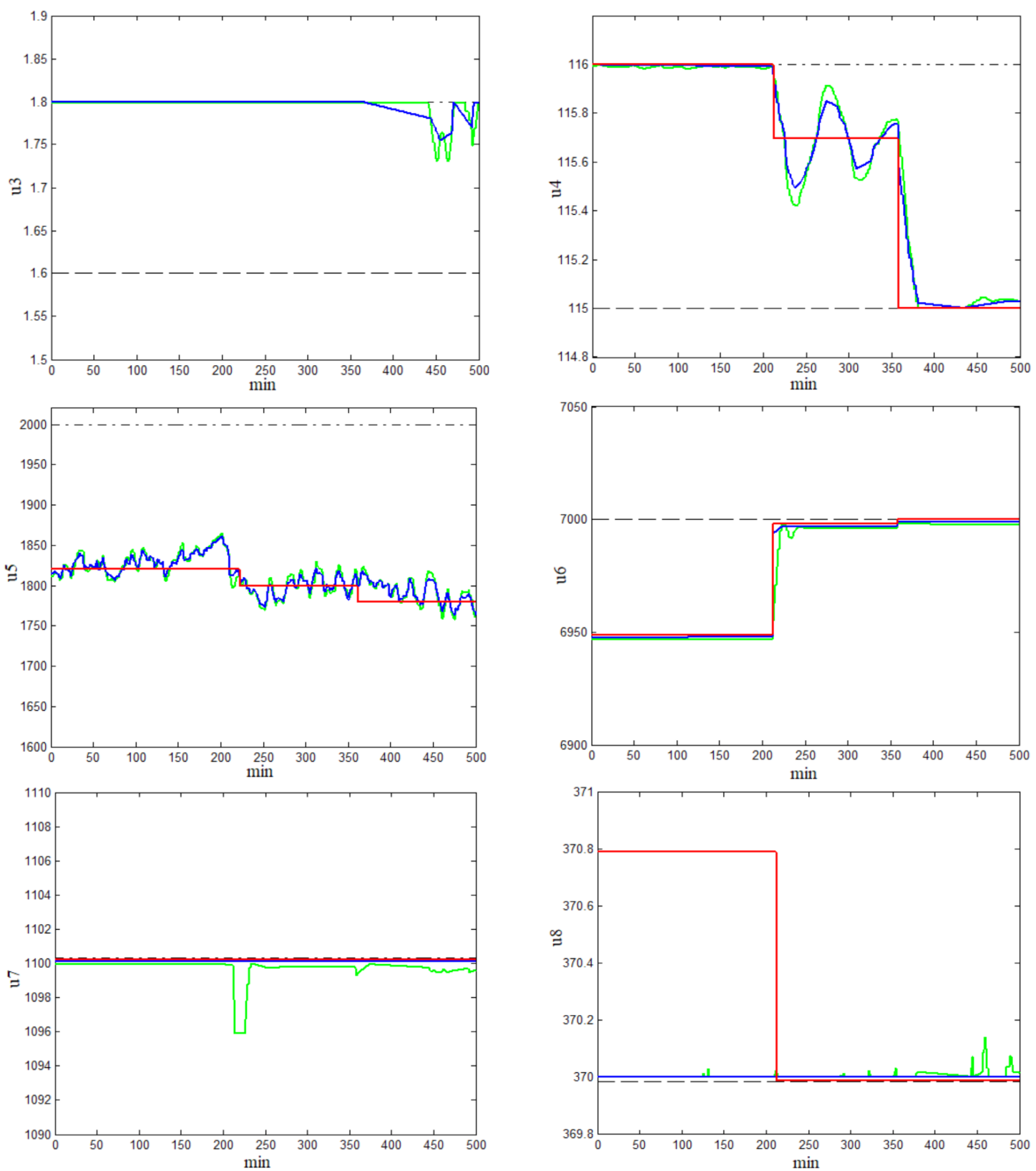

$-(u),-\left(u_{\min }\right),-\cdot-\cdot-\left(u_{\max }\right)$

Figure 8. Inputs of the Crude Distillation Unit (Case III).

followed the optimum values $u_{R T O}$ provided by the RTO layer.

Finally, it is important to note that with the tuning parameters defined in (22), a significant interaction was not observed between the static intermediary layer that defines the different steady-states considered in Case III. This means that on-line retuning of the parameters of the control structure may be a requirement to preserve the stability of the multilayer structure, if only a single model of the process is available.

\section{CONCLUSION}

This work reports some practical results related to the multi-layer integration of RTO and MPC in the industrial Crude Distillation Unit of the oil refinery at Capuava (Brazil). The main novelty is the consideration of an Infinite Horizon MPC, which is nominally stable, in an industrial Crude Distillation Unit of the oil refinery at Capuava (Brazil). The practical results collected from the Process Data Base of the refinery show that the multi-layer structure with IHMPC is not significantly better than the multi-layer structure with the conventional finite horizon MPC. However, if properly tuned, the IHMPC performs efficiently and can be used in practice with good results. This means that tuning of the intermediary static layer needs attention, otherwise the infinite horizon MPC can interact with the intermediary static layer that computes the feasible targets to the controller. This can lead to oscillations, 
lack of convergence or instability. This indicates that it may be justifiable to implement a robust controller where model uncertainty is implicitly considered. Also, when only the nominal model is considered and the IHMPC is implemented, special care should be taken with tuning of the multilayer structure. An integrated approach needs to be developed to help practitioners to implement such controllers. This work can be interpreted as an intermediate step in the process of the development and industrial implementation of a robust MPC, which may have a superior performance when model uncertainty is significant.

\section{REFERENCES}

Alvarez, L. A., Odloak, D. Robust integration of real time optimization with linear model predictive control. Computer and Chemical Engineering, 12, 1937-1944 (2010). https://doi.org/10.1016/j. compchemeng.2010.06.017

Ferramosca, A., Limon, D., González, A. H., Alvarado, I., Camacho, E. F. Robust MPC for tracking zone regions based on nominal predictions. Journal of Process Control, 22, 1966-1974 (2012). https://doi. org/10.1016/j.jprocont.2012.08.013

Forbes, M. G., Patwardhan, R. S., Hamadah, H., Gopaluni, R. B. Model Predictive Control in Industry: Challenges and Opportunities. IFACPapersONLine, 48, 531-538 (2015). https://doi. org/10.1016/j.ifacol.2015.09.022

González, A. H., Odloak, D. A stable MPC with zone control. Journal of Process Control, 19, 110-122 (2009). https://doi.org/10.1016/j. jprocont.2008.01.003

Hou, K., Li, Y., Shen, J., Hu, S. Crude distillation unit online optimization. Hydrocarbon Processing, 80, 69-75 (2001).

Jones, A., O’Donnel, M., Terndrup, H. Crude unit control and optimization at Grangemouth Refinery. Computing and Control Engineering, 10, 209-2013 (1999). https://doi.org/10.1049/cce:19990503

Kemalöglu, S., Kuzu, E. O., Çetin, D. O. G. Model predictive control of a crude distillation unit an industrial application. IFAC Proceedings Volumes, 7, 880-885 (2009). https://doi. org/10.3182/20090712-4-TR-2008.00144

Lee, J. H. Model predictive control: review of three decades of development. Journal of Control,
Automation and Systems, 9, 415-424 (2011). https://doi.org/10.1007/s12555-011-0300-6

Martins, M. A. F., Odloak, D. A robustly stabilizing model predictive control strategy of stable and unstable processes. Automatica, 67, 132-143 (2016). https://doi.org/10.1016/j.automatica.2016.01.046

Maciejowski, J. M. Predictive Control with Constraints, Prentice Hall (2002).

Mayne, D. Q., Kerrigan, E. C., Falugi, P., Robust model predictive control: advantages and disadvantages of tube based methods. IFAC-PapersOnLine, 18, 191-196 (2011). https://doi.org/10.3182/201108286-IT-1002.01893

Mingjian, S., Yude, S., Naizhang, F., Ma, C. Advanced RMPCT control strategy in CDU.IEEE International Conference in Robotics and Biomimetics ROBIO, Article number 4522524, 2273-2277 (2007). https://doi.org/10.1109/ROBIO.2007.4522524

Nogueira, D., Trivella, F. Multivariable control applied to a CDU: Capturing all the benefits with a large scope controller. NPRA Annual Meeting Papers, vol. 1, 16p (2002).

Pannocchia, G., Gallinelli, L., Brambilla, A. Rigorous simulation and model predictive control of a crude distillation unit. IFAC Proceedings Volumes, 39, 635-640 (2006). https://doi.org/10.3182/200604024-BR-2902.00635

Qin, S. J., Badgwell, T. A. A survey of industrial model predictive control technology. Control Engineering Practice, 11, 733-764 (2003). https:// doi.org/10.1016/S0967-0661(02)00186-7

Rawlings, J. B., Muske, K. R. The stability of constrained receding horizon control. IEEE Transactions on Automatic Control, 38, 1512-1516 (1993). https://doi.org/10.1109/9.241565

Santoro, B. F., Odloak, D. Closed-loop stable model predictive control of integrating systems with dead time. Journal of Process Control, 22, 1209-1218 (2012). https://doi.org/10.1016/j. jprocont.2012.05.005

Sun, J. N., Sun, M. J. Application of robust multivariable predictive control technology in CDU. Journal of Harbian Institute of Technology, 38, 1657-1660 (2006).

Yamashita, A. S., Zanin, A. C., Odloak, D. Tuning the Model Predictive Control of a Crude Distillation Unit. ISA Transactions, 60, 178-190 (2016). https:// doi.org/10.1016/j.isatra.2015.10.017 